\title{
X-ray Diffraction Techniques for Mineral Characterization: A Review for Engineers of the Fundamentals, Applications, and Research Directions
}

\author{
Asif Ali $\mathbb{C}^{\circ}$, Yi Wai Chiang (1) and Rafael M. Santos *(i) \\ School of Engineering, University of Guelph, Guelph, ON N1G 2W1, Canada; aali38@uoguelph.ca (A.A.); \\ chiange@uoguelph.ca (Y.W.C.) \\ * Correspondence: santosr@uoguelph.ca
}

check for

updates

Citation: Ali, A.; Chiang, Y.W.;

Santos, R.M. X-ray Diffraction

Techniques for Mineral

Characterization: A Review for

Engineers of the Fundamentals,

Applications, and Research

Directions. Minerals 2022, 12, 205.

https://doi.org/10.3390/

$\min 12020205$

Academic Editor: Ognyan E. Petrov

Received: 25 December 2021

Accepted: 3 February 2022

Published: 6 February 2022

Publisher's Note: MDPI stays neutral with regard to jurisdictional claims in published maps and institutional affiliations.

Copyright: (C) 2022 by the authors. Licensee MDPI, Basel, Switzerland. This article is an open access article distributed under the terms and conditions of the Creative Commons Attribution (CC BY) license (https:/ / creativecommons.org/licenses/by/ $4.0 /)$.

\begin{abstract}
X-ray diffraction (XRD) is an important and widely used material characterization technique. With the recent development in material science technology and understanding, various new materials are being developed, which requires upgrading the existing analytical techniques such that emerging intricate problems can be solved. Although XRD is a well-established non-destructive technique, it still requires further improvements in its characterization capabilities, especially when dealing with complex mineral structures. The present review conducts comprehensive discussions on atomic crystal structure, XRD principle, its applications, uncertainty during XRD analysis, and required safety precautions. The future research directions, especially the use of artificial intelligence and machine learning tools, for improving the effectiveness and accuracy of the XRD technique, are discussed for mineral characterization. The topics covered include how XRD patterns can be utilized for a thorough understanding of the crystalline structure, size, and orientation, dislocation density, phase identification, quantification, and transformation, information about lattice parameters, residual stress, and strain, and thermal expansion coefficient of materials. All these important discussions on XRD analysis for mineral characterization are compiled in this comprehensive review, so that it can benefit specialists and engineers in the chemical, mining, iron, metallurgy, and steel industries.
\end{abstract}

Keywords: X-ray diffraction; mineral characterization; crystal structure; Bragg's law; lattice parameters; crystallography; unit cell

\section{Introduction}

Materials are made up of atoms arranged in crystal microstructures [1]. Minerals are crystalline inorganic solids possessing well-defined chemical composition and are formed through natural processes. Minerals are usually classified and characterized based on their physical properties including hardness, color, crystallinity, flammability, and density. For example, calcite and magnesite possess high utility owing to their wide variety of applications in several industries including, paint, resin, ink, cosmetic, rubber, explosive, detergent, pharmaceutical, and construction industries [2,3]. In the Earth's crust, minerals are formed under certain thermodynamic and physicochemical conditions, which is demonstrated by their physical properties. External factors such as temperature, cooling rate during solidification, and pressure strongly influence the periodic arrangement of atoms in the structure. The solid-state compounds can be categorized as amorphous, single crystalline, and polycrystalline materials, based on the internal arrangement of atoms [4]. The nature of amorphous materials is isotropic owing to the irregular arrangement of atoms, which results in similar properties in all directions. Contrarily, the atoms in crystalline materials are arranged in a repeated and regular pattern, which exhibits changes in properties with direction (anisotropy) [5]. Various crystals of different sizes and shapes combine to form polycrystalline materials. The distribution of crystal shapes, orientations, and sizes in a polycrystalline material strongly affect its properties [6]. The nature of about $95 \%$ of the 
solid materials is crystalline [7], and International Center for Diffraction Data (ICDD) has maintained a database of crystals and powders for about 460,900+ inorganic and 51,400+ organic entries [8].

X-rays have wavelengths comparable to atomic size, and therefore, intensities of $X$-ray diffraction technique or diffraction patterns are used for harnessing information about atomic structures. For instance, X-ray diffraction (XRD) is used for examining and characterizing the position of atoms, their arrangement in each unit cell, and spacing between the atomic planes [9]. XRD is a non-destructive testing technique, which can be employed for examining a wide variety of materials including minerals, polymers, plastics, metals, semiconductors, ceramics, and solar cells [10]. This technique is also extensively used in power generation, aerospace, microelectronics, and other industries [11].

Although X-ray crystallography has quite wide applications in industry, it has remained a complex field of study. There have been several literature studies on the applications of XRD and scarce reviews have been conducted on technical information of crystal structures and XRD. Hart [12] analyzed various methods for Bragg's angle measurement based on the information related to general XRD principles and the arrangement of crystals in the subject material. It was found that single-crystal methods are prevalent in many terms, for the case of $\Delta \mathrm{dd}>10^{-4}$. Fewster [13] assessed several methods of lattice parameter measurement. This study revealed that the type of crystal arrangement plays a significant role in the selection of appropriate measurement techniques. Magner et al. [14] studied the role of XRD in measuring the retained austenite content in heat-treated steels for ensuring product quality. They investigated historical developments of XRD methods, applications, and techniques from the early 1930s related to austenite retention. Jesche et al. [15] examined the procedures for lattice spacing measurement. They synthesized guidelines for investigating single crystals of dimensions over $200 \mu \mathrm{m}$. An inclusive resource for understanding the basics of XRD and X-ray powder method is referred here for the beginners [16]. Referring to these studies provides some basic XRD understanding to the relevant engineers.

Crystallography is often taken as a training or tertiary-level course by chemists, geologists, and metallurgists. However, the basic understanding of X-ray crystallography and crystal structure is not fully apprehended by most engineers. The present article aims at reviewing the technical and systematic information about the crystal structure, $\mathrm{XRD}$, and its connection with practical applications for providing an introductory self-training.

\section{Crystal Structure}

Arrays of atoms are arranged in a repeated and regular pattern in crystalline structures. The smallest recurring element of crystal is known as a unit cell, while the size and shape of the unit cell (Figure 1) can be explained by the angle between axes $(\alpha, \beta, \gamma)$ and length of three axes $(a, b, c)$ [7] in a three-dimensional system. Atoms in an array are arranged in order, based on the position of atoms (translation or transformation) while no change is found in terms of orientation or rotation. The type of translation may be one-, two-, or three-dimensional [17]. A regular arrangement of points in a crystal is a lattice. Figure 1a,b, represent the lattice structure of crystals in two- and three-dimensions, respectively.

The mathematical concept of space lattice was introduced by Bravais in 1848 for describing the arrangement of crystal structure (Figure 2). The scattering of an infinite number of points in space is illustrated by space lattice so that the arrangement of points around a point is similar to any other point [18]. The points arrangement in space lattice is designated by the $x, y, z$ axes system (Figure 1). Figure 2 indicates 14 lattices, which are a demonstration of all possible points arrangements in a three-dimensional space lattice. Based on the angles between axes, their lengths, and their symmetry properties, 14 Bravais lattices can be categorized into 7 crystal systems.

In crystallography, space groups represent the description of crystal symmetry. These are ways with which a crystal's orientation can be changed without changing the position of atoms in it. The orientational changes include the translation of crystal structure, along 
with in-place reflection, rotation about an axis, sequential rotary inversion, or inversion about a center. The combination of these changes can lead towards 230 distinct sequences, which are known as space groups. The inherent symmetry of crystal can be categorized by assigning it to one of these 230 space groups [19-23].

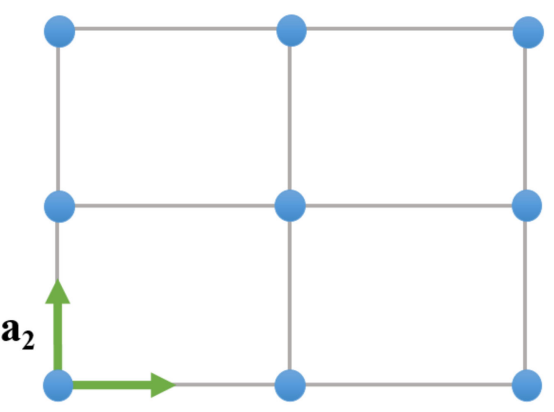

$\mathbf{a}_{1}$

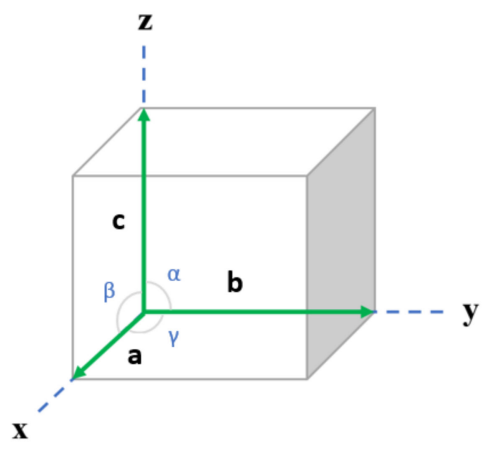

(b)

(a)

Figure 1. (a) Two-dimensional lattice with translation vector (b) Three-dimensional lattice with translation vector.

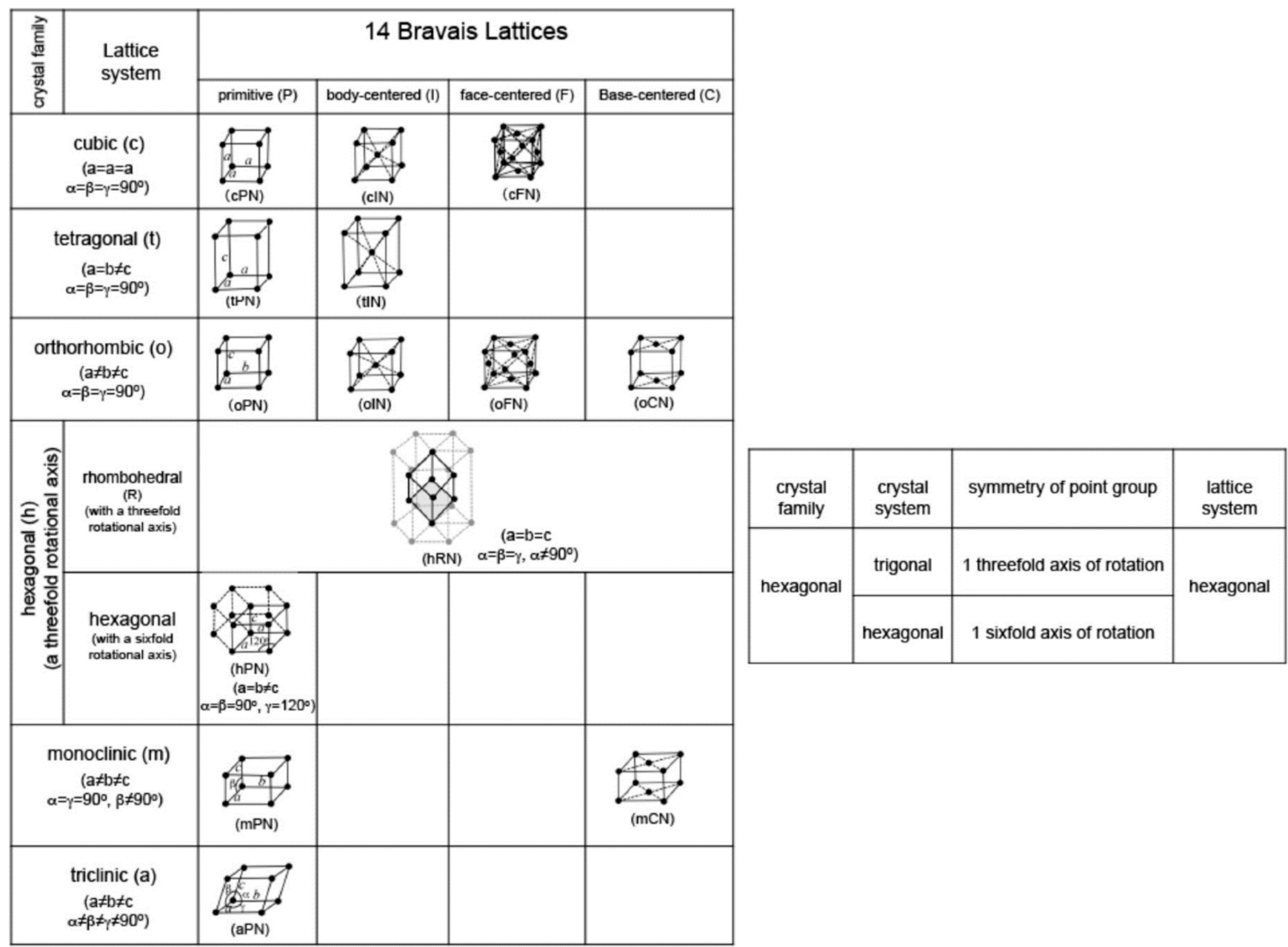

Figure 2. Various configurations of Bravais lattices [24]. CC-BY.

\section{X-ray Diffraction Principle}

When the X-rays impinge on solid materials, they become scattered by the electrons revolving around the nucleus of atoms. These scattered waves, emitted in multiple directions, 
interfere with each other. The nature of interference can be constructive or destructive, based on the direction and type of interaction of waves [25]. Diffraction is the constructive interference of scattered X-rays. It is worthy to note here that the orderly arrangement (periodicity) of atomic structures in solids causes constructive interference. It is, therefore, apparent to clearly interpret the XRD graphs of crystalline substances. A strong correlation exists between periodicity and diffraction, i.e., higher diffraction angles are observed with shorter periodicity and vice versa [25]. Lamas et al. [26] demonstrated XRD graphs of amorphous and crystalline solids, as shown in Figure 3a,b, respectively. Due to the absence of a periodic arrangement in amorphous materials, the XRD graph only indicates the maximum average peak at a certain diffraction angle, while crystalline materials show several distinct XRD peaks owing to the periodic arrangement of atoms. XRD is also a powerful technique for estimating the treatment effects on the crystallinity of materials. For example, a recent study [27] used XRD for understanding the effects of various treatments on the crystallinity of their sample material. XRD allowed them to identify that the combustion treatment of their sample would enhance the material's crystallinity to a relatively greater extent, as shown in Figure 4.

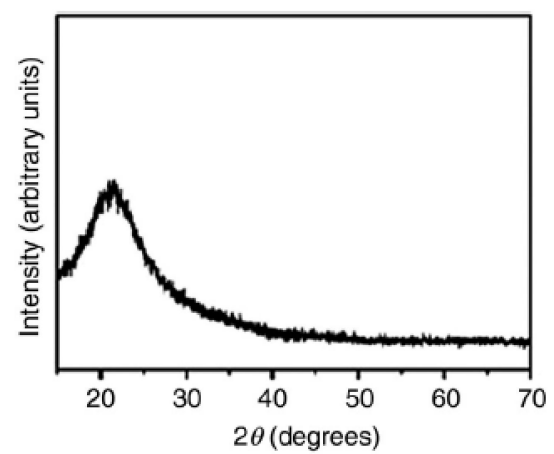

(a)

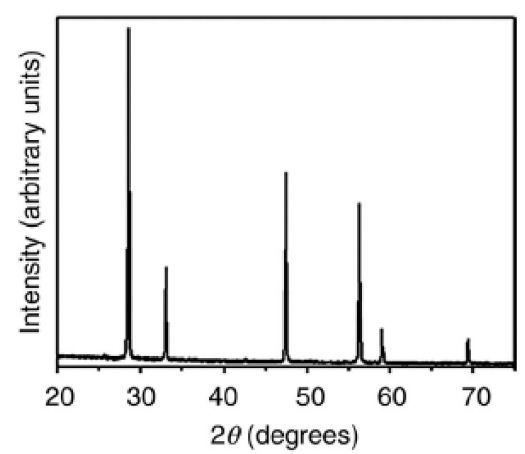

(b)

Figure 3. XRD qualitative graphs that represent (a) an amorphous material [26] and (b) a crystalline material [26]. Re-used with permission from Elsevier (5116510855423).

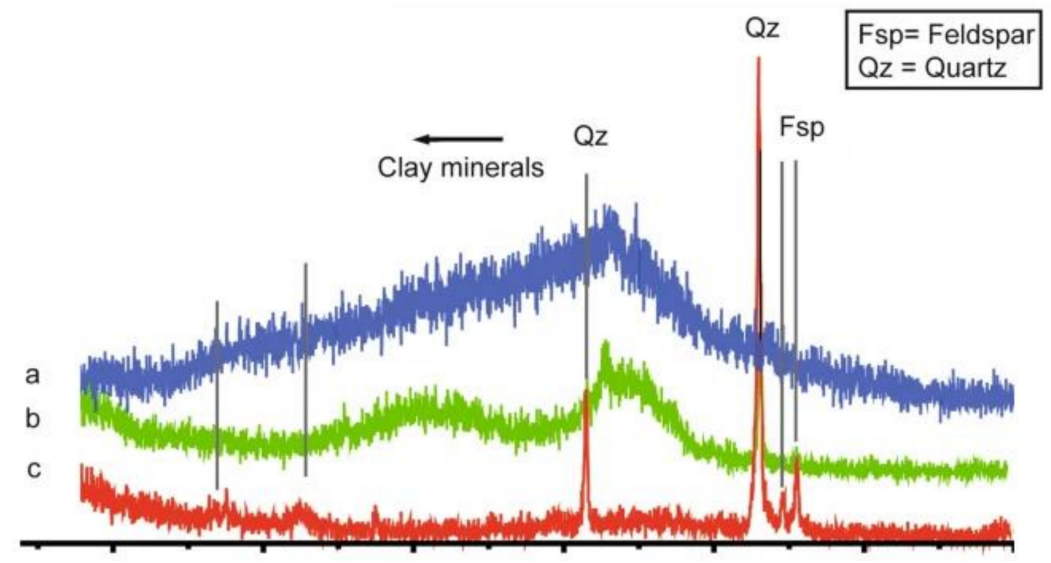

Figure 4. XRD was used for understanding the role of various treatments on the crystallinity of peat (a mixture of organic matter and minerals): (a) sample material without treatment (blue); (b) $\mathrm{H}_{2} \mathrm{O}_{2}$ chemical oxidation treatment (green); (c) combustion treatment (red) [27]. CC-BY.

Knowledge about the atomic number and atomic position within the cell is determined by diffraction peak intensity, while diffraction peak position provides information about the size and shape of the unit cell [28]. Figure 5 illustrates the XRD spectrum of a clay sample [29]. It can be visualized that XRD analysis enables the identification of several minerals present in the sample. For example, five $Q$ peaks are observed with varying peak 
positions and intensities, indicating a variety of atomic positions, the size, and the shape of the quartz unit cell.
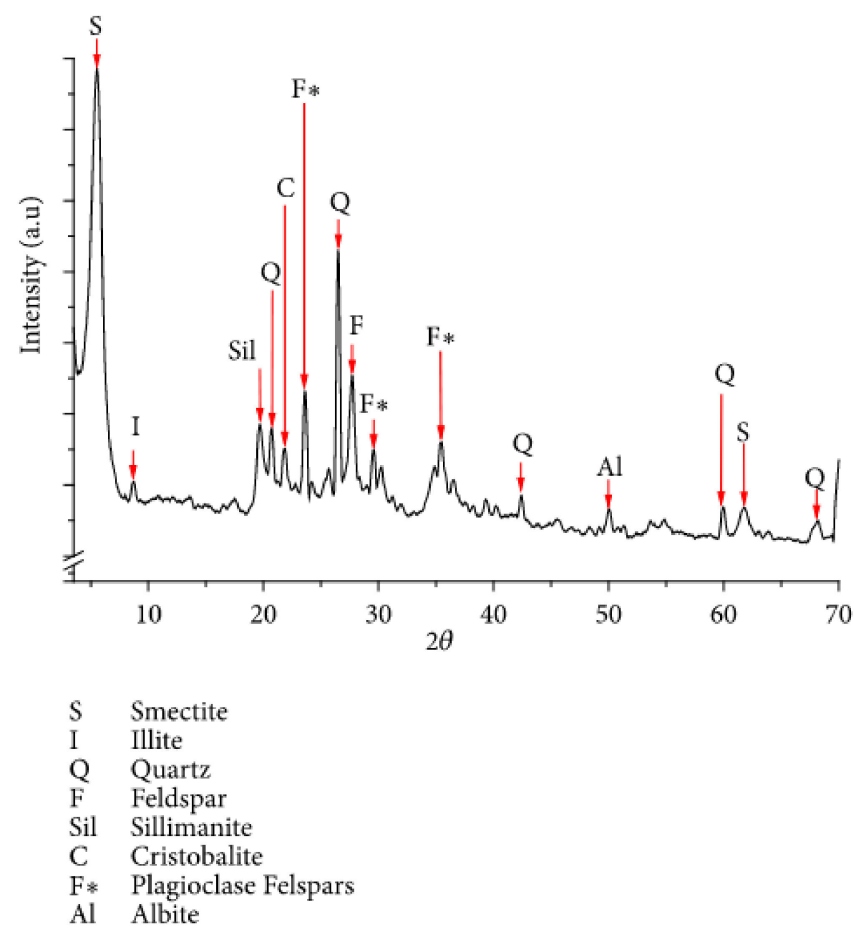

Figure 5. X-ray diffractogram of clay sample [29]. CC-BY.

\subsection{Bragg's Law}

Laue discovered XRD and afterward, an alternative measurement technique and simple explanation for monochromatic X-ray diffraction was proposed by Bragg [30]. According to Bragg's analysis, the atomic planes (lattice planes- $h k l$ ) or crystals are assumed to be in layers. A distance $d$ separates these layers, as shown in Figure 6a, and impingement of incident X-ray or light on these atomic planes produces reflection [31]. At the lattice planes, the angle between the incident beam and equivalent diffracted wave remains equal. As diffraction is constructive interference of scattered waves, when path difference lengths become equal to $n \lambda$, Bragg's diffraction condition gets satisfied.

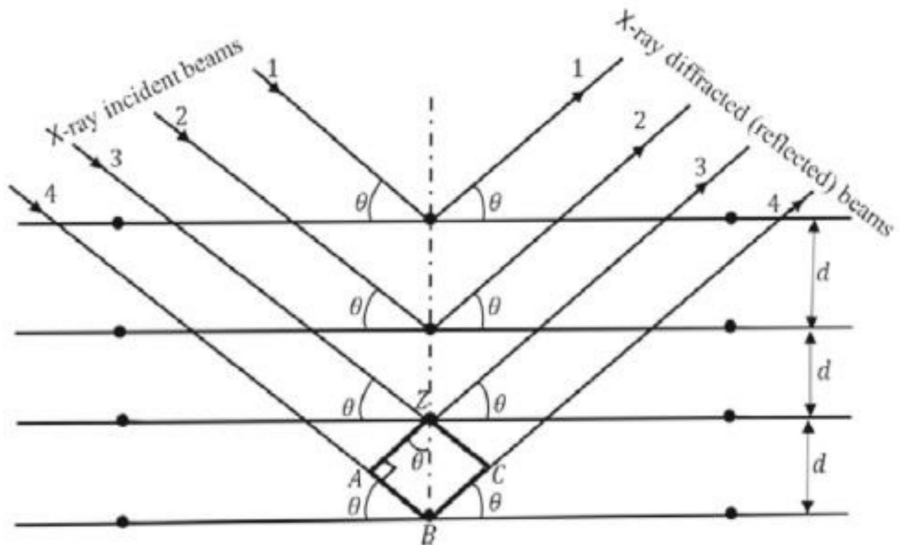

(a)

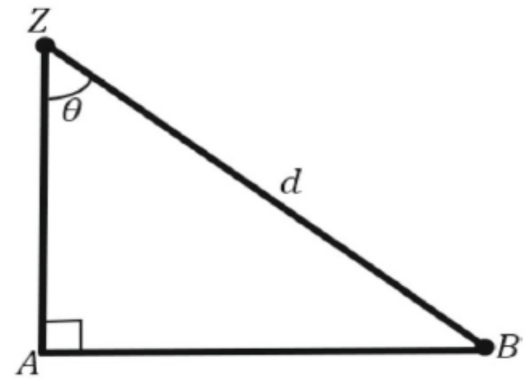

(b)

Figure 6. (a) An illustration of X-ray diffraction pattern [31]; (b) Pythagoras theorem applied for deriving diffraction equations [31]. Re-used with permission from Oxford Publishing Limited (53905). 
Pythagoras theorem (Figure 6b) was used for deriving the following equations till Equation (5). As per Bragg's law, the condition for constructive interference is [31]:

$$
A B+B C=n \lambda
$$

From schematic of XRD (Figure 6a), it can be inferred that $A B=B C$ :

$$
2 A B=n \lambda
$$

The Pythagoras theorem is applied on $\triangle A B Z$ and $A B$ is inserted to yield Equation (5) as follows:

$$
\begin{aligned}
& \sin \theta=\frac{A B}{d} \\
& d \sin \theta=A B \\
& n \lambda=2 d \sin \theta
\end{aligned}
$$

where $n$ indicates the order of reflection (diffraction), $\lambda$ denotes $X$-ray wavelength, $d$ characterizes spacing between atomic planes, and $\theta$ represents diffraction beam angle. The set of lattice planes $(h k l)$ with spacing $\left(d_{h k l}\right)$ can be related with the order of diffraction $(n)$ as follows:

$$
d=\frac{d_{h k l}}{n}
$$

With the substitution of Equation (6) into Equation (5), the following relation is found:

$$
\lambda=2 d_{h k l} \sin \theta_{h k l}
$$

The vector notation of Bragg's law can be illustrated with the directions of incident and scattered beams, as schemed in Figure 7. Moreover, Bragg's law in vector form can be expressed as follows [32]:

$$
\frac{\left(S-S_{o}\right)}{\lambda}=d_{h k l}^{*}=h a_{1}+k a_{2}+l a_{3}
$$

where $S$ represents the unit vector with the direction of diffracted beam and $S_{o}$ indicates unit vector in direction of the incident beam.

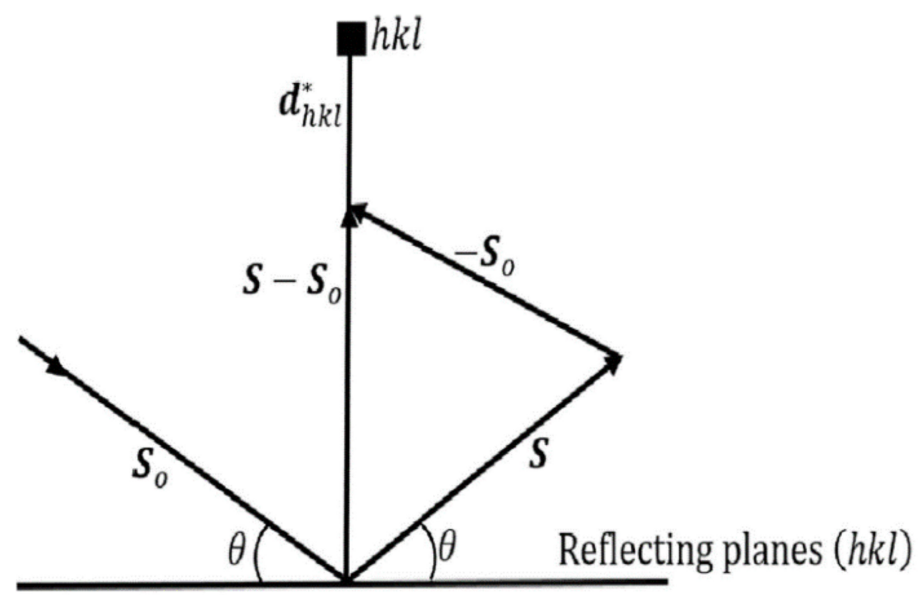

Figure 7. Schematic representing the vector notation of Bragg's law [33]. Re-used with permission from Oxford Publishing Limited (53906).

\subsection{Laue Equations}

Laue equations are based on Ewald theory and it opened up a way for the discovery of XRD [30]. According to these equations, the proper orientation of crystal structure in three-dimensions satisfies the diffraction process. It is, therefore, the assumption of Laue 
equations that atomic rows build up the crystal structure in three dimensions. Figure $8 \mathrm{a}$ represents the constructive interference of waves. The wave crest of the incident beam $(A B)$ diffracts due to the presence of atoms in the $z$-direction, and the wave crest of the diffracted beam is indicated as $C D[18,33]$. The constructive interference of waves is witnessed by the path difference of diffraction, as it equals the integer multiple of the wavelength of the incident wave [17]. On the contrary, if it is not an integral multiple of its wavelength, this indicates destructive interference. Figure $8 \mathrm{~b}$ represents the vector notation of incident and diffracted X-ray beams, as illustrated by Laue's law, and consequent path difference between diffracted waves.

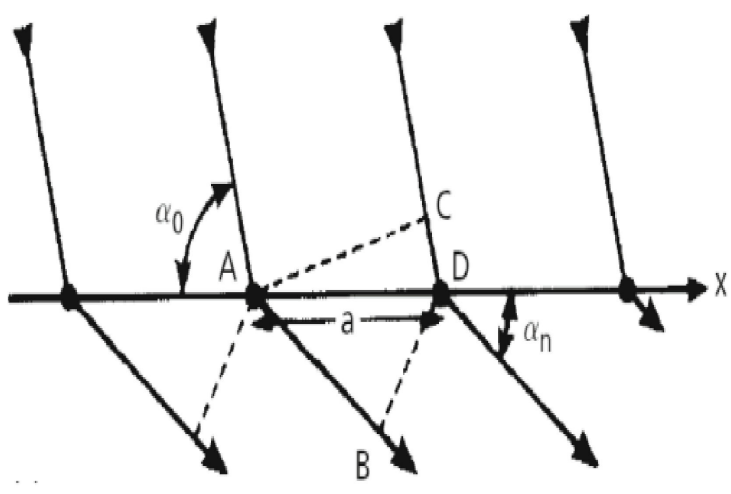

(a)

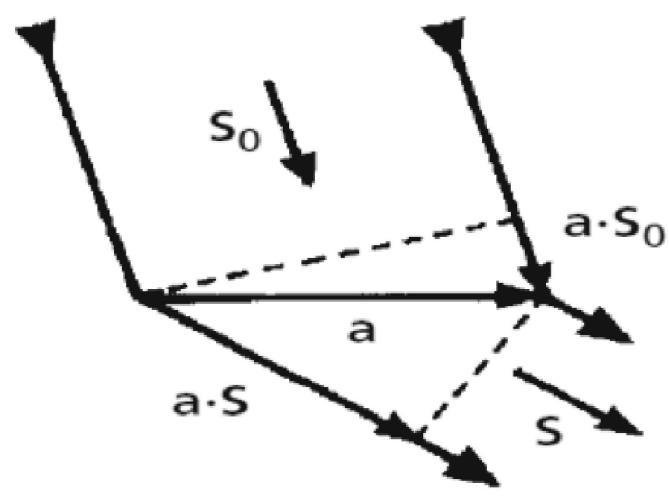

(b)

Figure 8. (a) Diffraction of X-ray beams from atomic rows in $\mathrm{x}$-direction [21]; (b) Vector representation of incident, diffracted X-ray beams, and path difference [21]. Re-used with permission from Elsevier (5116510855423).

Laue first equation is mathematically expressed for path difference $(A B-C D)$ related to the constructive interference as follows:

$$
(A B-C D)=a\left(\cos \alpha_{n}-\cos \alpha_{o}\right)=n_{x} \lambda
$$

where $a$ indicates lattice parameter featuring atomic spacing in $x$-axis direction, $\alpha_{n}$ represents diffracted beam angle to the $x$-axis, $\alpha_{0}$ denotes incidence angle concerning the $x$-axis, while $n_{x}$ implies the integral diffraction order. Laue first expression (Equation (9)) can be represented in vector notation concerning the $x$-axis using Laue cones (plotted in Equation (10)) as follows [33]:

$$
a\left(\cos \alpha_{n}-\cos \alpha_{o}\right)=a_{1}\left(S-S_{0}\right)=n_{x} \lambda
$$

Since X-ray beams with similar path differences diffract at similar angles relative to an atomic row, three Laue cones (Figure 9) would be an adequate representation of diffracted beams falling on rows of atoms. The angles of three Laue cones are $\alpha_{0}\left(n_{x}=0\right.$, zero order), $\alpha_{1}\left(n_{x}=1\right.$, first-order $)$, and $\alpha_{2}\left(n_{x}=2\right.$, second-order $)$.

Similarly, for $y$ - and $z$-axis atomic rows, Laue second and third expressions can be written as follows $[33,34]$ :

$$
\begin{aligned}
& b\left(\cos \beta_{n}-\cos \beta_{0}\right)=a_{2}\left(S-S_{0}\right)=n_{y} \lambda \\
& c\left(\cos \gamma_{n}-\cos \gamma_{0}\right)=a_{3}\left(S-S_{0}\right)=n_{z} \lambda
\end{aligned}
$$

where the atomic spacing in the $y$-axis and $z$-axis is given by $b$ and $c$, respectively. The angles $\beta_{n}$ and $\gamma_{n}$ are diffraction X-ray angles while $\beta_{o}$ and $\gamma_{o}$ are incident X-ray angles from the $y$-axis and $z$-axis, respectively. 


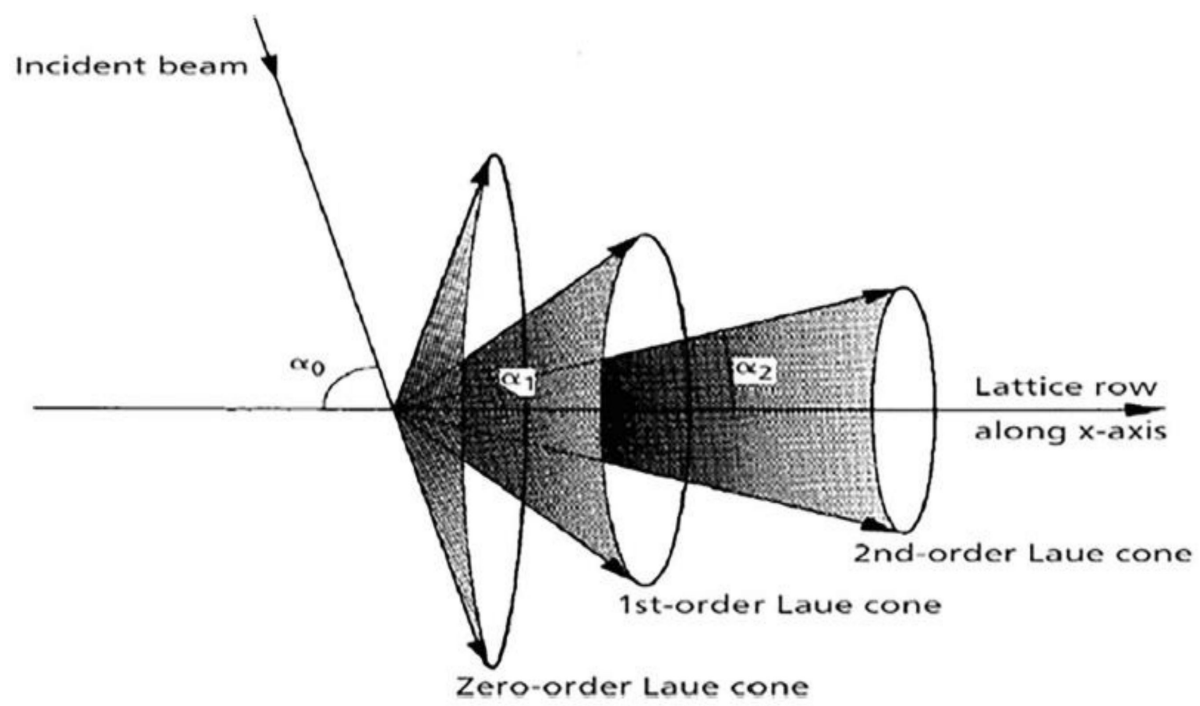

Figure 9. Schematic showing three Laue cones of diffracted X-ray beams directed relative to lattice atomic rows changing from $0^{\circ}$ to $180^{\circ}$ [33]. Re-used with permission from Oxford Publishing Limited (53906).

\subsection{Ewald Theory}

The relationship between distances of oscillators and wavelength of light has been proposed by Ewald [35]. His theory is acceptable for any light wavelength to distancing oscillator ratio and remains valid without approximation. Ewald sphere construction consists of reciprocal lattice and reflection sphere. It is a criterion used for determining whether the diffraction condition for reciprocal lattice point is valid or not [33]. Figure 10 demonstrates the construction of the Ewald sphere. Suppose a diffracting crystal is placed at the center of the Ewald sphere (at a distance $1 / \lambda$ from point of incidence) and an incident beam $I$ passes through sphere diameter $I O$. The origin of reciprocal lattice $O$ is defined by the exiting point of the incident beam from the sphere. $B$ represents the exit point of the diffracted beam. A vector $O B$ is achieved if a certain orientation of crystal meets Bragg's law criteria for X-ray diffraction [36]. Consequently, it can be stated that the length of vector $O B$ is equivalent to $\frac{1}{d_{h k l}}[37]$.

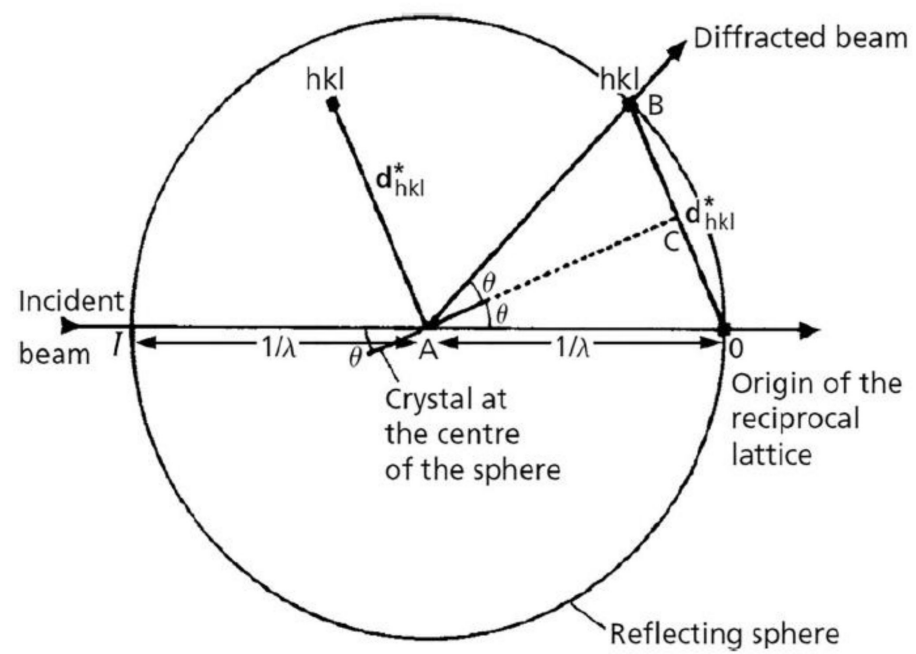

Figure 10. The construction of the Ewald sphere indicates a set of planes on diffraction position [33]. Re-used with permission from Oxford Publishing Limited (53906). 
Reciprocal lattice vector $d_{h k l}^{*}\left(=\frac{1}{d}\right)$ represents reciprocal space distance or reciprocal lattice point. Thus, the condition of Bragg's law is met once reciprocal lattice point corresponding to reflecting planes $h k l$ transects Ewald sphere [13]. From $\triangle \mathrm{AOC}$ of Figure 10:

$$
|O C|=\frac{1}{\lambda} \sin \theta=\frac{1}{2}\left|d_{h k l}^{*}\right|=\frac{1}{2 d_{h k l}}
$$

The vector notation of the Ewald sphere illustrating Bragg's law can be stated as under [33]:

$$
\frac{\left(S-S_{o}\right)}{\lambda}=d_{h k l}^{*}=k-k_{o}
$$

where $k_{o}$ shows vector $O A, k$ represents vector $A B$, and $d_{h k l}^{*}$ indicates the reciprocal lattice vector, as the origin of reciprocal lattice shifts from $A$ to $O$.

Reciprocal space is the Fourier transform of the real space. Owing to this concept, an array of delta functions in reciprocal space over a lattice $(h k l)$ would be generated by an infinite array of scatterers in real space. The positions of these delta functions get fixed by the repeated units, while their intensities are attributed to the details of scattering density distributions. Defects and smaller crystals tarnish the continuity of delta functions, and this concept gives an understanding of peak broadening in XRD.

\section{Applications of X-ray Diffraction in Mineral Characterization}

$\mathrm{X}$-ray diffraction is a powerful non-destructive technique for mineral characterization having wide applications within major domains such as crystal structure and size, phase identification, crystallographic orientation, determining the lattice parameters, dislocation density, residual stress/strain, phase transformation, and thermal expansion coefficient [28].

\subsection{Phase Identification and Quantification}

There is a unique set of interplanar spacing and relative intensities or a distinct XRD pattern to every crystalline mineral (or solid) which serves as its fingerprint [7]. Hence, $\mathrm{XRD}$ is used for determining diffraction intensities and peak positions of a specimen while Bragg's law is used for calculating corresponding interplanar spacings. Therefore, constituent phases can be identified by computerized searching in an unknown sample. It can be proceeded by matching the strongest peak intensity line with recorded interplanar spacing values stored in a database, namely the joint committee on powder diffraction standard (JCPDS), while using peak intensity of the strongest line as a function of the weight of phases in a mixture can be used for phase quantification [38]. Scientific investigations have revealed that in addition to pure mineral composition, XRD can also provide data about the proportions of minerals in a mixture [39,40]. XRD produces superior information in qualitative, quantitative, and structural analyses of crystalline minerals. It performs well with phases proportions in minerals. Its full spectrum fitting method of Rietveld refinement can be used for revealing structural and content information of all phases present in the sample mixture [41].

Wang et al. [42] synthesized fly ash coated with a metal-organic framework, namely ZIF-8 nanocomposites, and investigated their performance as an adsorbent of nickel, copper, and zinc ions from aqueous solutions. They used the XRD technique for analyzing the synthesis of nanocomposite materials. First, they analyzed the XRD diffractogram (Figure 11) of fly ash, which indicated significant phases of mullite and quartz crystals, followed by hematite and wollastonite. Figure 12 represents the peaks of both fly ash and ZIF-8 materials present in the composite structure, which ensured proper coating and synthesis of nanocomposite material.

XRD technique provides insights about crystalline structures, however; it does not reveal any valuable information about amorphous materials-a limitation. For example, a recent study from Hamilton et al. [43] studied mineral carbonation using XRD and total carbon measurement. They have found that XRD only reveals information of carbon sequestration in minerals owing to crystalline structure alone. According to them, it is an 
underestimation of carbon sequestration by minerals because of the presence of amorphous structures such as $\mathrm{Mg}$-carbonates. Their investigation and analyses uncovered that the XRD technique is helpful in mineral carbonation quantification, but underestimates sequestrated carbon accounting by about four times, and therefore suggested using both XRD and total carbon data for an in-depth estimation of carbon sequestration through minerals. So, XRD is a useful technique for the identification and quantification of crystalline phases. It can also incorporate some methods like standard addition, internal standard, and reference internal ratio (RIR), combined with peak and background fitting, integral and Rietveld refinement calculations, to determine the amorphous content in the sample relative to the total crystalline phase content. However, recent uses of synchrotron have allowed wider investigations in the field of amorphous or poorly-crystalline solids [44].

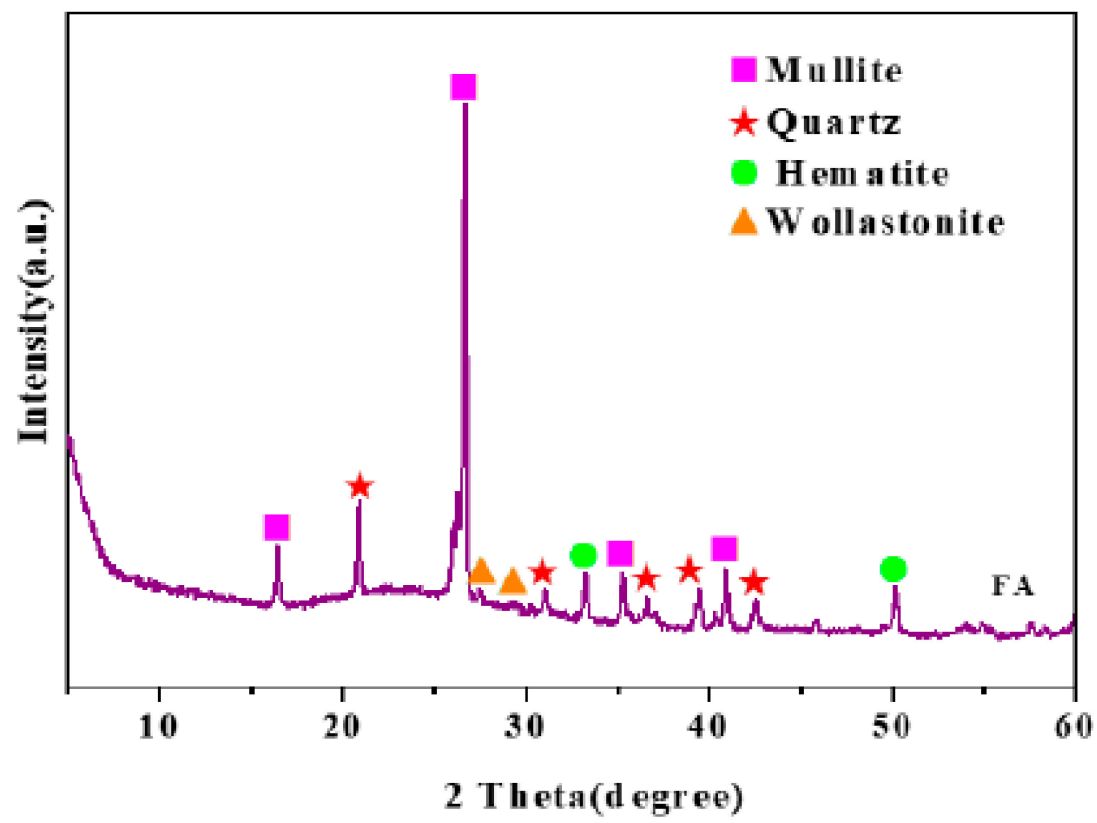

Figure 11. XRD diffractogram of fly ash [42]. CC-BY.

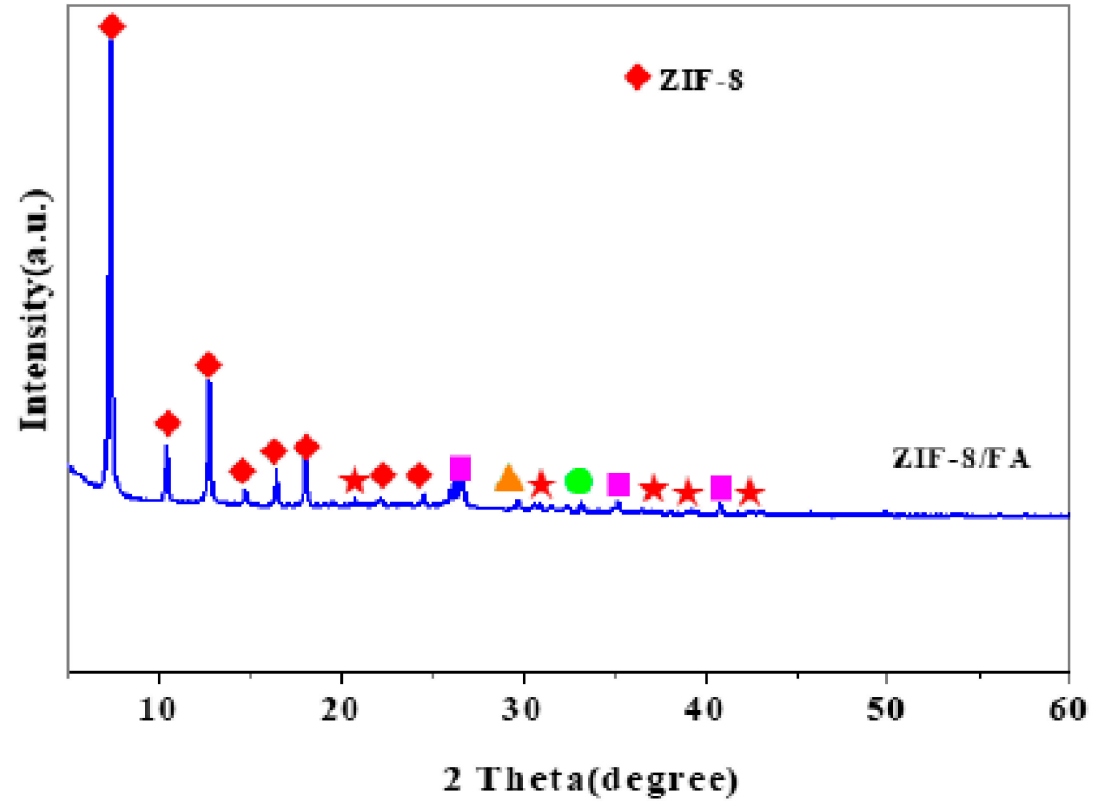

Figure 12. XRD diffractogram of coated fly ash with ZIF-8 [42]. CC-BY. 


\subsection{Lattice Parameters}

The physical and chemical properties of minerals are influenced by the arrangement of atoms in the crystal structure. Lattice parameters can significantly affect the properties of minerals. These parameters are also known as unit cell parameters because they express the shape and size of unit cells and crystals. The six parameters, as shown in Figure 1, include the length of three axes, i.e., $a, b, c$, and three subsequent angles between them, i.e., $\alpha, \beta$, $\gamma$ [16]. The atomic position in crystals gets notified by diffraction peak intensities while the shape and size of a unit cell, which gets influenced by the above-mentioned parameters, is illustrated by position of diffraction peaks. Thus, measurement of peak position from XRD diffractogram, over a range of $2 \theta$, can be used for determining lattice parameters. While Bragg's law can be used for mathematically expressing these unit cell parameters [16]. The peaks on the XRD diffractogram can be indexed for the identification of the planes, responsible for each peak. The reflections can be indexed by assigning the correct $h k l$. The planes with the largest $d$-spacing would represent the smallest Bragg angle. Additionally, several computer-based software programs can be used for pattern indexing. The lattice parameters can then be determined using least-squares analysis, once the powder pattern is indexed. After it, the translational symmetry elements and the Bravais lattice of the mineral structure can be examined for any systematic absences. This procedure aids in identifying the space group or, at minimum, narrows the choice to two or three types of space groups [1]. Today, there are plenty of software packages available (like High Score Plus, SIROQUANT, DIFFRAC.TOPAS, MAUD, etc.) that can be used to analyze the XRD data [45-47].

\subsection{Crystalline Structure}

As discussed in Section 2, it is important to have information about the basic crystal structure of a mineral for its efficient utilization in real-world applications. Important parameters that are required for identifying a crystalline structure are the number of atoms per unit cell, coordination number and packing factor of these atoms, and lattice parameters and lattice points of atoms in a unit cell of crystalline structure [24]. XRD aids in finding this set of information which is then used for the identification of crystal structure. When the sum of miller indices (i.e., $h+k+l$ ) of principal diffracting planes equals an even number, the crystal structure of minerals is considered to have a BCC structure. On the other hand, when all miller indices $(h, k, l)$ of diffracting planes are all even or all odd numbers, the crystal structure is identified as FCC $[48,49]$. The crystals of minerals can be refined using a method proposed by Rietveld in 1969 [50]. This technique refines a theoretical line profile based on the least-squares approach, relative to the measured profile. It refines the least-squares line until it matches the measured one.

Rojas-Mantilla et al., recently characterized the nontronite mineral present in clay [51]. Nontronite contains structural iron in higher proportions. They considered the effects of iron impregnation $(45 \% \mathrm{Fe})$ and heat treatment $\left(\right.$ at $\left.600{ }^{\circ} \mathrm{C}\right)$ on the mineral characterization using XRD, as indicated in Figure 13. Before any treatment, the XRD diffractogram is shown in Figure 13a, while Figure 13b indicates the XRD graph after heat treatment, and Figure 13c shows the effect of iron impregnation and heat treatment. They reported that the nontronite phase concentration became reduced after heat treatment, while iron impregnation brought it down further. They attributed this behavior to the rearrangement of nontronite crystals after heat treatment and the formation of hematite on its surface. XRD allowed them to identify the minerals present in the clay sample and empowered them to identify the changes with physical treatment processes. The variations in crystal structure occurring due to heat treatment and iron impregnation were caught by XRD and demonstrated how the crystallinity of components varies with these processes. 


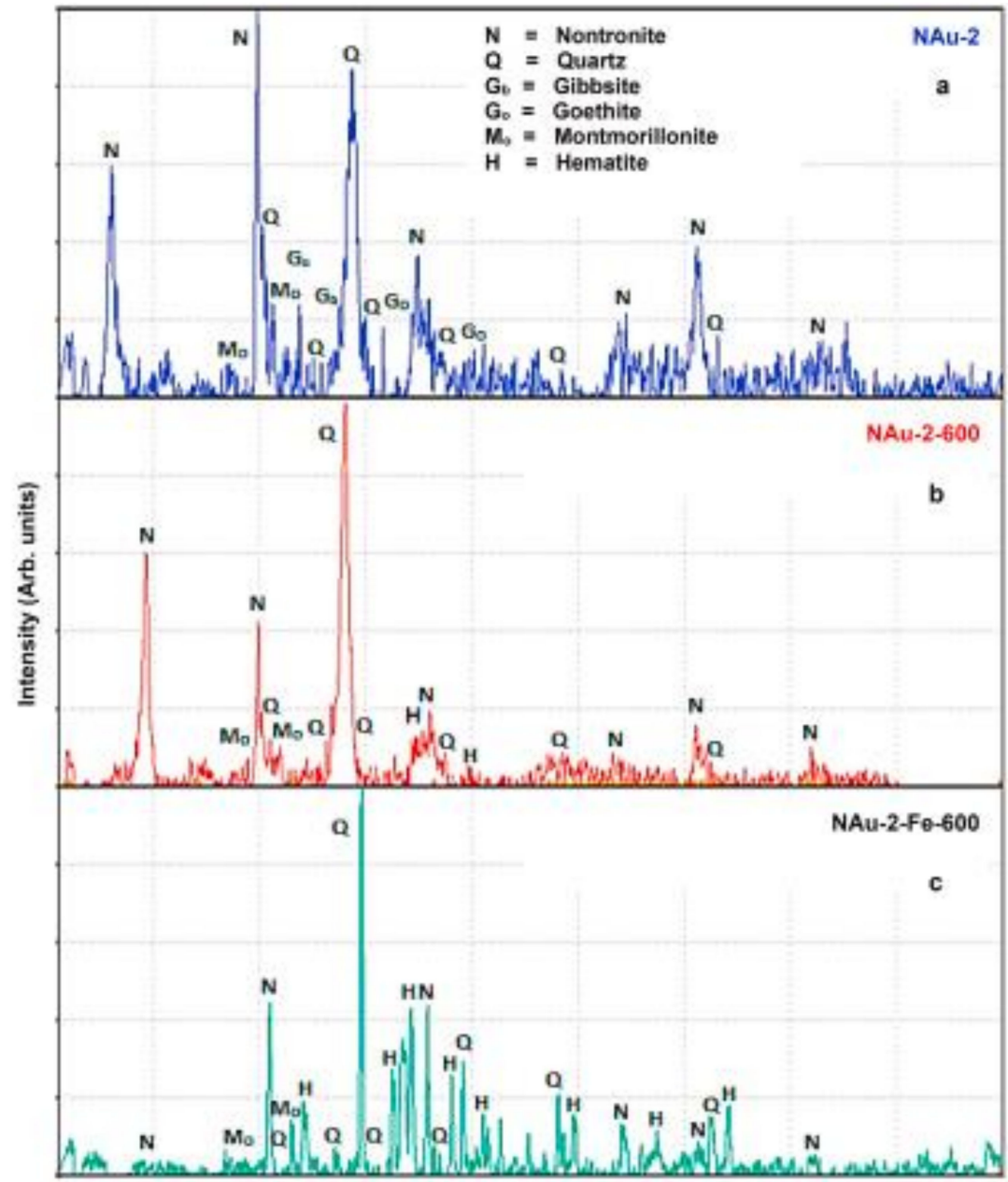

Figure 13. XRD plots of (a) nontronite sample before any treatment; (b) Sample after heat treatment; (c) Sample after iron impregnation and heat treatment [51]. Re-used with permission from Elsevier (5116421005778).

\subsection{Crystal Size and Orientation}

Generally, the activity of a mineral in soils can be described by the size of diffracting crystallites, since the reduction in particle size often results in increasing its surface area. XRD can be useful for determining the size of particles. However, XRD patterns of the mixtures of minerals in soils can be complicated for identification. Usually, the minerals present in the soil can be segregated into particle-size fractions and complications are resolved by analyzing the minerals separately [52].

The principle that decreasing grain or crystalline size leads towards increasing diffraction width, which is also known as peak broadening, is used for determining the size of grains. Thus, widening of an XRD peak is an indicator that small crystallite does not contain enough planes viable for producing complete destructive interference $[53,54]$. The size of particles can be estimated through the following Scherrer equation [55]:

$$
D=\frac{K \lambda}{B \cos \theta}
$$

where $D$ indicates the size of the particle, $K$ is Scherrer constant $=0.9, \lambda$ represents XRD wavelength, $B$ denotes full width at half maximum (FWHM) measured in radians, and $\theta$ is diffraction angle.

Crystallographic orientation is the spherical distribution of crystals in polycrystalline aggregates. Its quantification can be estimated by evaluating the orientation distribution function (ODF) which implies orientation density as a function of rotation angle [56]. 
The calculation of ODF can be carried from pole figures either by series expansion or direct inversion method [57]. The physical and mechanical properties of materials are affected by crystallographic orientation and distribution. Several engineering materials and minerals are characterized physically and mechanically by crystallographic orientation [58]. Preferential crystallographic orientation may avoid diffraction of some planes depending on orientation of crystals.

\subsection{Phase Transformation}

The process of phase transformation and outlining phase diagrams could be conducted through various methods, including transmission electron microscopy, electrical resistivity, nuclear magnetic, scanning calorimetry, and XRD [59]. However, information on phase identity on both sides of the phase boundary is provided by XRD, which makes it a productive tool for studying the phase transformation of minerals. The compositional phase and quantity on the phase diagram are dependent on alloying content, timing, and heat treatment temperature [60]. There is wide use of XRD in phase transformation investigations. XRD is also being used in alloying compositions as it maps out regions with various crystal phases. Another high-utility area of XRD is the temperature-compositional phase diagram of a compound [61]. With the continuous recording of XRD patterns, any shift in peak position due to a change in lattice constant can be identified while the sample is being heated/cooled. It is because the lattice constant is a strong function of compositional phase and temperature [61,62]. Consequently, changes in peak positions or in diffraction patterns corresponding to phase presence and phase boundary are recorded accordingly for a given temperature [60]. Ashiri et al., synthesized tetragonal barium titanate nanoparticles using xerogel at low temperatures [63]. Raising the temperature of xerogel from $800{ }^{\circ} \mathrm{C}$ to $1100{ }^{\circ} \mathrm{C}$ with increments of $100{ }^{\circ} \mathrm{C}$ resulted in peak splitting at about $2 \theta=45^{\circ}$, as shown in Figure 14. It indicates polymorphic transformation with heat treatment of the sample. The use of the XRD non-destructive technique empowered them to identify the phase transformation during tetragonal barium titanate synthesis.

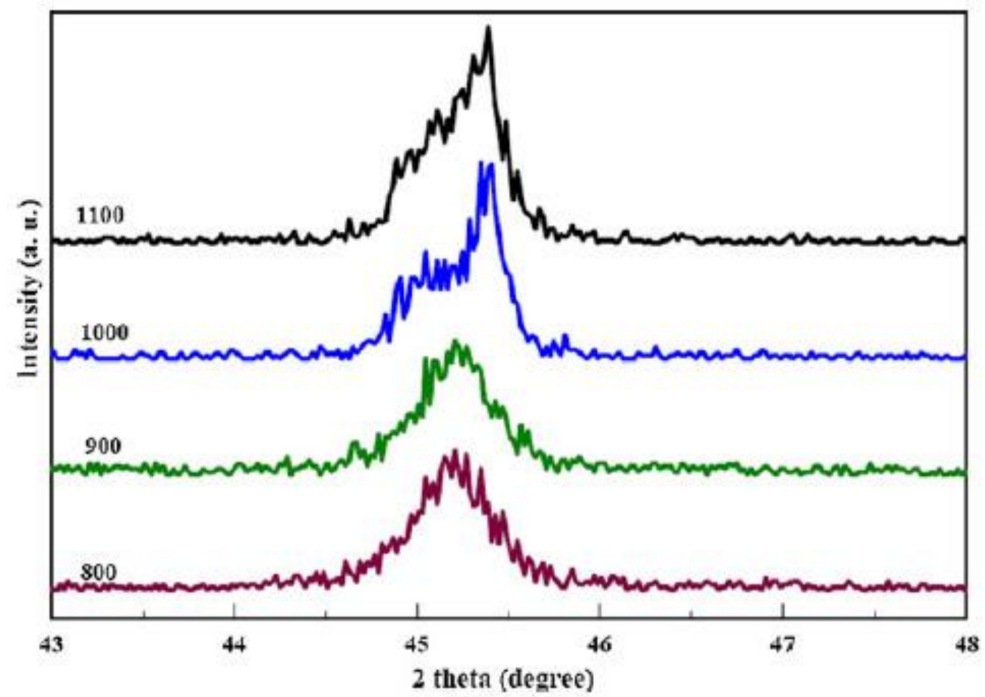

Figure 14. XRD graph of xerogel treated at various temperatures, illustrating peak broadening [63]. Re-used with permission from Elsevier (5116430928360).

\subsection{Residual Stress and Strain}

After the removal of external force, the remaining stress in the crystal structure is known as residual stress. XRD helps in residual stress and strain investigations by allowing interplanar space measurement through high diffraction peaks of a sample. This information then reveals the distribution of angular lattice strain, which becomes the foundation of residual stress analysis [64]. Subsequently, Hook's law is used for the computation 
of average internal residual stress within a crystal using strain values obtained from the Williamson-Hall plot. Singh et al., investigated the sub-atmospheric sputtering pressure changes on the growth of residual stress in $\mathrm{ZnO}$ films on $\mathrm{SiO}_{2} / \mathrm{Si}$ substrate [65]. The peak shifting with increasing sputtering pressure indicates higher residual stresses in the sample, as shown in Figure 15.

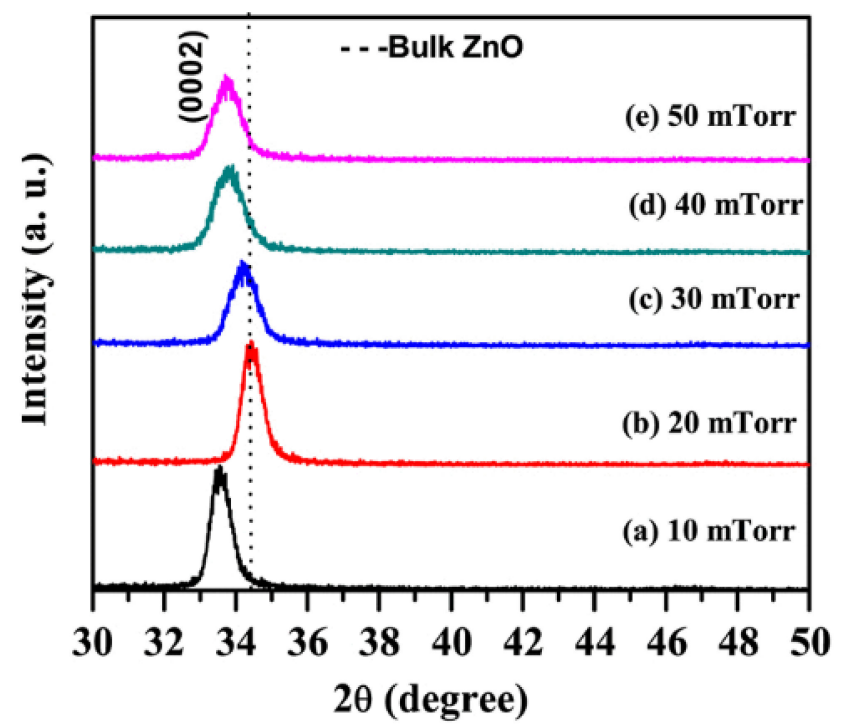

Figure 15. XRD pattern of $\mathrm{ZnO}$ film with varying sputter pressures [65]. CC-BY.

\subsection{Dislocation Density}

Dislocation, an irregularity formed within a crystal, causes lattice defect, which is indicated by an equal broadening of XRD peaks [66]. The term dislocation density refers to the length of dislocated lines per unit crystal volume. Increasing strain and decreasing grain size result in augmenting dislocation density [67]. The following relation may be used for estimating dislocation density $(\delta)$ [68]:

$$
\delta=\frac{15 B \cos \theta}{4 a D}
$$

where, $B$ indicates the width of (111) peak at half maximum intensity, $a$ represents lattice constant, and $D$ denotes grain size (average).

\subsection{Thermal Expansion Coefficient}

Physical properties of materials such as mechanical, electronic, and optical properties significantly depend upon thermal expansion coefficient, especially at elevated temperatures $[69,70]$. The expansion coefficient of materials is reliably estimated with high-temperature XRD. The underlying principle behind this XRD technique for coefficient measurement is the Rietveld analysis of powder XRD [71].

With increasing temperature, increased atomic vibrations are observed around their mean position, due to which intensities of XRD beams become reduced [71,72]. Hence, lattice parameter values are influenced by temperature which makes it important to record the XRD pattern of the sample at every given temperature during heating or cooling operations. Lattice parameters are expressed, with polynomial models, as a strong function of temperature for estimating thermal expansion coefficients of materials [73].

\subsection{Examples of XRD-Characterized Minerals and Complementary Techniques}

As XRD has been used for identification and characterization applications of several minerals, some recent valuable publications are listed in Table 1 for readily bringing the readers to the state-of-the-art of this technology. 
Table 1. Recent XRD applications related to identification, quantification, and characterization of minerals, and complementary techniques used.

\begin{tabular}{|c|c|c|c|}
\hline Techniques/Methods & Year & Minerals/Materials & Reference \\
\hline XRD and Raman & 2021 & Ilmenite, pyrite, chromite, chalcopyrite & [74] \\
\hline XRD, FTIR, SEM-EDX & 2021 & Quartz, illite, augite, kaolinite, calcite etc. & [75] \\
\hline XRD, MLA & 2021 & Scheelite, fluorite, pyrrhotite, pyrite & [76] \\
\hline XRD, XRF, EPMA & 2021 & Clay minerals & [77] \\
\hline XRD, Raman Spectroscopy, HRTEM & 2021 & Coal, graphite & [78] \\
\hline XRD, FTIR, SEM, TG-DTA, SEM-EDS & 2020 & Pulverized fuel ash, slag, magnesium oxysulfate cement & [79] \\
\hline XRD, TG-DTA & 2020 & Fly ash with sand and glass powder & [80] \\
\hline XRD, XRF, SEM-EDS & 2020 & Sandstones and their mineral components & [81] \\
\hline XRD, FTIR, SEM, AFM, TGA, GC & 2020 & Raw coal and acid washing coal & [82] \\
\hline XRD & 2020 & Upper Murray formation, Vera Rubin Ridge, Gale Crater & [83] \\
\hline XRD, XPS, ICP-OES & 2020 & Ilmenite, titanaugite, olivine & [84] \\
\hline XRD, XRF, SEM-EDS & 2019 & Manganese & [85] \\
\hline XRD, SEM, SEM-EDX & 2019 & $\begin{array}{l}\text { Certified reference materials including soil, dust, } \\
\text { sediment, leaves, dates, and fish }\end{array}$ & [86] \\
\hline XRD, FTIR & 2019 & Silica polymorphs & [87] \\
\hline XRD, FTIR, TG-DTA, MIP, SEM & 2019 & $\begin{array}{l}\text { Ground granulated blast-furnace slag, fly ash, } \\
\text { cement mortars }\end{array}$ & [88] \\
\hline XRD, FTIR, XPS & 2019 & Graphene oxide, nano alumina & [89] \\
\hline XRD, XRF, SEM, PSA & 2018 & $\mathrm{SiO}_{2}, \mathrm{Na}_{2} \mathrm{SiO}_{3}$ & [90] \\
\hline $\begin{array}{l}\text { XRD, RIR, MIF, Rietveld, Full } \\
\text { Pattern Summation }\end{array}$ & 2018 & Clay minerals & [91] \\
\hline XRD, NMR, GNMD & 2018 & Clay minerals, hectorite & [92] \\
\hline In-situ XRD, Isothermal Calorimetry & 2018 & Fly ash, metakaolin, slag & [93] \\
\hline $\mathrm{XRD}, \mathrm{XRF}$ & 2018 & Clay minerals, mica, mudrock & [94] \\
\hline XRD, ICP-OES, HRTEM & 2017 & Clay minerals, bioapatite & [95] \\
\hline XRD, conventional sintering, cold sintering & 2017 & Sillimanite & [96] \\
\hline
\end{tabular}

XRD $=$ X-ray Diffraction, XRF $=$ X-ray Fluorescence, SEM $=$ Scanning Electron Microscope, PSA $=$ Particle Size Analyzer, RIR = Reference Intensity Ratio, MIF = Mineral Intensity Factor, NMR = Nuclear Magnetic Resonance, GCMD = Grand Canonical Molecular Dynamics, FTIR = Fourier Transform Infrared Spectroscopy, XPS = X-ray Photoelectron Spectroscopy, TG-DTA = Thermogravimetry-Differential Thermal Analysis, MIP = Mercury Intrusion Porosimeter, ICP-OES = Inductively Coupled Plasma Optical Emission Spectrometry, HRTEM = High-Resolution Transmission Electron Microscopy, SEM-EDX(S) = Scanning Electron Microscope with Energy Dispersive X-ray Analysis (Spectroscopy), GC = Gas Chromatograph, TG/DTA = Thermogravimetry/Differential Thermal Analysis, MLA = Mineral Liberation Analysis, EPMA = Electron Probe Micro-Analyzer.

\section{Uncertainty}

\subsection{Constraints}

The XRD analyzing instrument is expensive and requires considerable capital cost, while maintenance and operational costs are smaller than other analogous diagnostic devices [97]. XRD works quite well with single-phase and homogenous minerals; however, it does not demonstrate accuracy with mixed materials, with which the detection limit of $\mathrm{XRD}$ is about $4 \mathrm{wt}$ \% of the sample. XRD requires minerals to be grounded in powder form, so even tenths of grams of the precious minerals need to be grounded for XRD analysis. Another limitation is related to the accessibility of inorganic compounds' standard files ( $h k l s$, $d$-spacing), as it is probably considered a must-needed tool for the XRD data processing. Sometimes, peak overlay obstacle is found in XRD analysis, which further complicates the process for high angle reflections. Moreover, the indexing of non-isometric crystal patterns for unit cell and space group determination is an intricate process.

\subsection{Sources of Error}

The errors associated with preparation and type of sample, and operation of XRD instrument contribute majorly towards peak analyses errors.5.2.1. Sample Related Errors

(1) Preferred orientation error: This problem arises when crystallites in a texture or powder show a stronger tendency towards one way more than all the others. Random orientation of the sample is required for identifying phases based on peak intensities. 
A systemic error is introduced within peak intensities due to the preferred orientation of crystallites and plates. For minimizing the order/disorder variability of amorphous materials, standards are $100 \%$ crystalline [98].

An example of preferred orientation during sample processing has been illustrated in Figure 16 [97]. $\mathrm{Ag}(100 \mathrm{~nm}) / \mathrm{Al}(30 \mathrm{~nm})$ bilayers were annealed in $\mathrm{NH}_{4}$ at $725^{\circ} \mathrm{C}$ and $625^{\circ} \mathrm{C}$ and the XRD spectra $(\theta-2 \theta)$ formed an Al-encapsulation layer on the surface. Results revealed a strong texture for $\mathrm{Ag}(111)$ which increases further at high temperature $\left(725^{\circ} \mathrm{C}\right)$ annealing. The preferred orientation of the samples affects their intensity. Another study from Silva et al., showed that the preferred orientation problem can be minimized by giving special attention to the sample preparation stage [99].

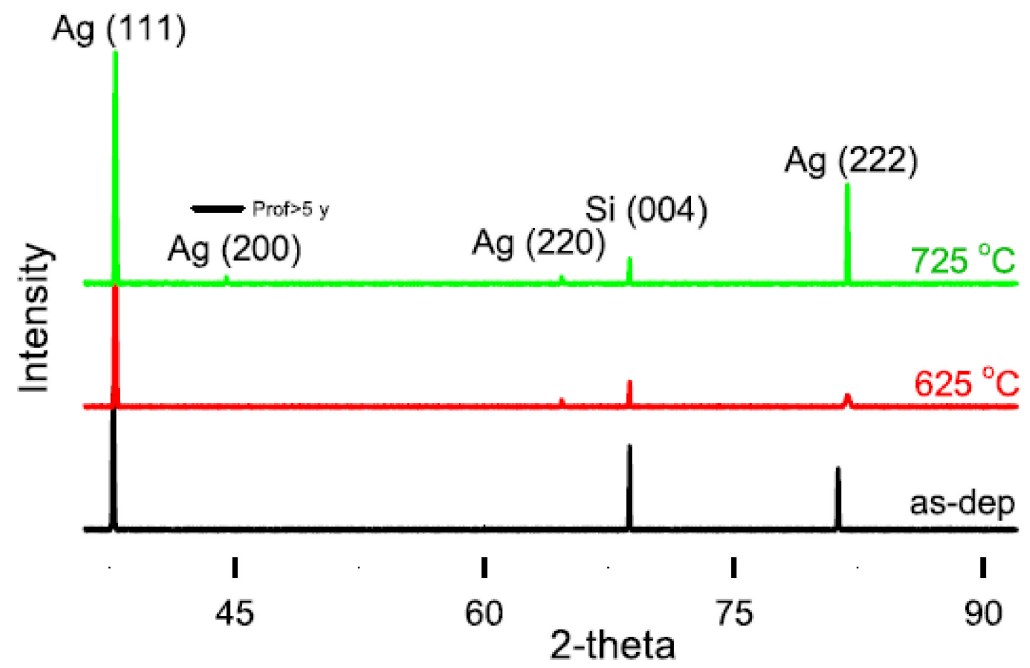

Figure 16. Encapsulated Ag layers with annealing temperatures of $725^{\circ} \mathrm{C}$ and $625^{\circ} \mathrm{C}$ are described by XRD data [97]. Re-used with permission from Elsevier (5116430634401).

(2) Vertical/axial divergence error: The peak asymmetric broadening gets reduced and diffracted intensity reaches its maximum with capillary lenses, Soller slits, and reduction in the vertical opening of the counter slit. This phenomenon occurs because the X-ray beam in the plane with the sample shows divergence [100].

(3) Peak shape error: Quantification of amorphous materials is compromised, as these materials typically demonstrate asymmetrical and broad peaks.

(4) Microabsorption: It is considered the greatest obstacle in the way of quantitative phase analysis with powder XRD data. This error has its roots associated with the interaction of each material with the X-ray beam, on-die geometrical peculiarities of their distribution, and volume fractions of involved components (large particles not crystallites) [101]. The materials susceptible to microabsorption errors are complex composites including geological materials, concrete/cement, and coal combustion by-products (CCBs). The absorption of X-ray radiation by each material is dependent on the material's linear absorption coefficient related to the unique energy (wavelength) of the X-ray wave. For instance, the adsorption coefficient of CCBs using copper radiation ranges from $1153 \mathrm{~cm}^{-1}$ for magnetite to $81 \mathrm{~cm}^{-1}$ for quartz. This error usually degrades XRD accuracy when sample phases have a wide variety of X-ray absorptions [102]. It becomes minimized with milling and grinding operations, which result in smaller particle sizes.

(5) Counting statistics: When the particle size is less than $10 \mu \mathrm{m}$, optimum statistical characterization of powders is obtained. Peak intensity variations occur due to non-random orientation and large crystallite sizes. These diffractograms demonstrate contradictory behavior as compared to ideal powder (which is measured for multiple randomly oriented crystallites). It is, therefore, difficult to identify these diffractograms with reference patterns in the Powder Diffraction File (PDF) database. 
(6) Sample displacement error: The movement of the sample coerces XRD beams to miss the aperture of the detector. Figure 17A indicates displacement of a sample with dashed lines above green block (representing sample), while the XRD beam missing the detector is shown by solid lines vs. dashed lines. Due to this reason, the peak position is wrongly reported by the instrument. The following relation can be used for identifying the displacement error $s$ :

$$
\Delta 2 \theta=-\frac{2 s \cos \theta}{R}
$$

where $R$ is the goniometer radius. The displacement of $s=0.15 \mathrm{~mm}$ corresponds to a peak shift of $0.08^{\circ}$ at $R=200 \mathrm{~mm}$ and $2 \theta=28.4^{\circ}$. Displacement error gets minimized with the use of parallel-beam optics, while algorithms require internal calibration standards for compensating displacement errors.

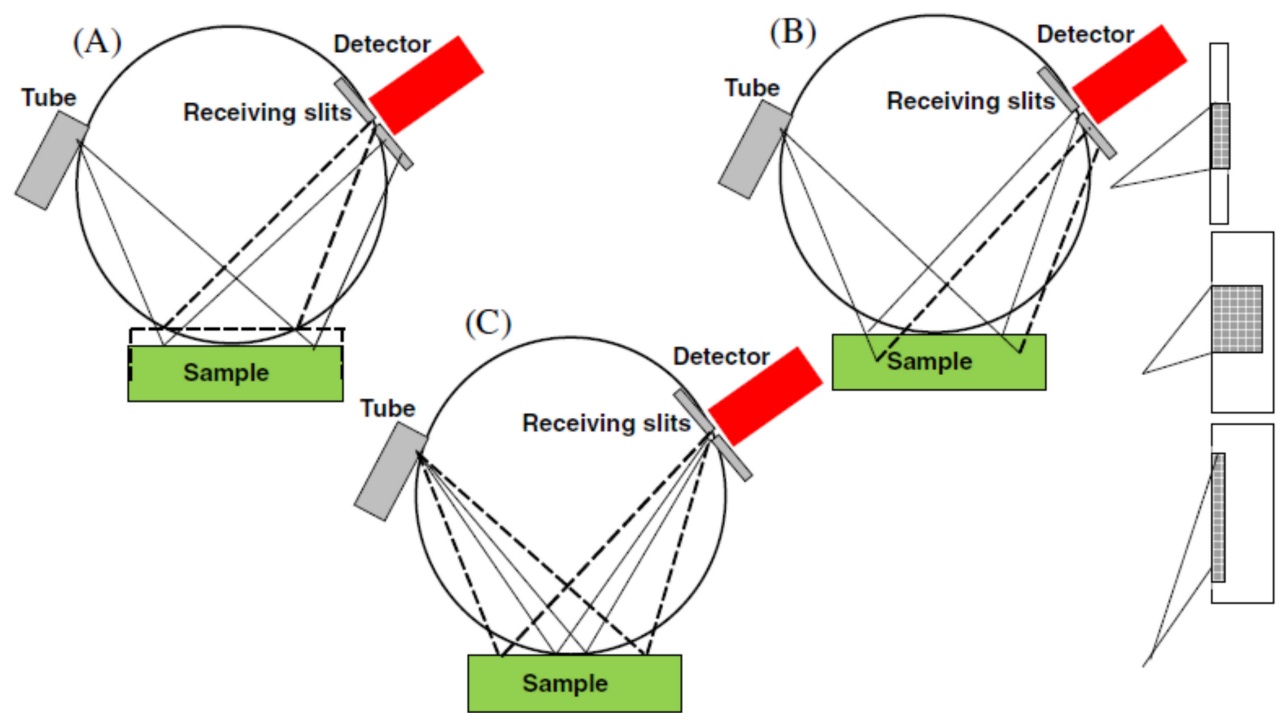

Figure 17. XRD sample-based errors as illustrated by (A) Sample displacement error; (B) Sample transparency error and (C) Flat sample error [97]. Re-used with permission from Elsevier (5116430634401).

(7) Sample transparency error: The depth of X-ray penetration is majorly influenced by the incident angle of the $X$-ray beam and mass absorption coefficient $\mu$ of the specimen. Peak symmetry and peak position errors are mostly seen in low absorbing (low atomic number) and organic specimens. These errors are introduced owing to various XRD beams arriving from different points, as described by dotted lines vs. solid lines in Figure 17B. Transparency error can be minimized by the use of parallel beam optics and thin specimens.

(8) Plate sample error: This error usually arises when the flat surface of the sample is not able to lie completely on the focusing circle, as shown in Figure 17C. The resulting peaks are asymmetric and broader (especially at lower $2 \theta$ angles). Plate sample error becomes reduced with the use of narrow divergence slits with shorter beams and parallel beam optics.

\subsubsection{Instrumental Errors}

(1) Equipment misalignment error: The offset of the instrument gives rise to this "zero" $2 \theta$ position error. A systematic peak position error is introduced with this instrumental offset, and peak position error remains proportional to $2 \theta$ [103]. For avoiding such errors, all components including the sample, source, and detector should be in line at $0^{\circ} \theta$ angle.

(2) Sample fluorescence error: This error arises when electrons of certain elements, including $\mathrm{Ga}, \mathrm{V}, \mathrm{Zn}, \mathrm{Mn}, \mathrm{Cr}, \mathrm{Cu}, \mathrm{Ni}, \mathrm{Fe}$, and $\mathrm{Co}$ become excited due to incident X-ray radiation. The characteristic $\mathrm{X}$-rays are emitted from excited electrons and recorded signals at the detector are found near $\mathrm{Cu} \mathrm{K} \alpha$, which does not affect intensity or position, however, increases background noise. Energy-sensitive detectors, $\beta$ filters, monochromators, and 
pulse height distribution levels (PHD) can be used for reducing the fluorescence influence on the signal. Although sample fluorescence can cause errors during XRD analyses, the same phenomena of X-ray emission are used for the identification of elements present in the mineral sample. This technique is known as X-ray fluorescence (XRF), which also determines the concentration of mineral elements [104].

\subsubsection{Compositional Variations Errors}

(1) Grinding: Samples reveal various transformations such as loss of volatile components, decomposition with local heating, strain, and amorphism with excessive grinding operations. Some engineered materials, zeolites, and clays are damaged in a low-temperature environment. A tail of very fine particles is produced with ball-mills or shatter boxes, which results in broadening XRD peaks. Brittle grinding media such as tungsten carbide may contaminate the sample and may cause the introduction of additional peaks in the diffractogram. This type of error can be reduced with mortar and pestle, and other non-percussive methods [105].

(2) Environment: Solids expand with elevated temperatures, which encourages stress and strain in the sample. Other known environmental factors are the presence of water and other liquids, which interact with the sample (made up of zeolite or clay minerals, etc.) and change its structure [106].

\subsection{Detection Limits}

The absolute and relative standard distribution (SD), $\sigma$ and $\sigma_{r e l}$, can be given as follows by using the rules of Poisson distribution for $N$ counts at $2 \theta$ :

$$
\begin{gathered}
\sigma=\sqrt{X} \\
\sigma_{r e l}=\frac{\sqrt{X}}{X}=\frac{1}{\sqrt{X}}
\end{gathered}
$$

Furthermore, the limit of detection (LOD) for a specific reflection can be expressed as under:

$$
X_{\text {reflection }}>X_{\text {background }}>3 \sigma_{\text {background }}
$$

\subsection{Quantification Limits}

The lower limit of quantification (LOQ) is an important parameter for the analysis of multiphase samples. It is crucial to know about the smallest quantity of a given phase in the sample that can be detected by XRD. Several factors affect LOQ such as peak overlap, preferred orientation, amorphous content, and matrix effect crystal symmetry. Normally, a calibration curve can be used for determining the LOQ of a particular phase. The value of LOQ varies with the composition of samples, however, practitioners have cited an LOQ of 5 wt.\% [97].

\subsection{Crystallinity}

The crystallinity of the sample is defined by the ratio of total diffraction intensities $\left(N_{n e t}\right)$ and the sum of all measured intensities $\left(N_{t o t}\right)$, including the amorphous portion. The air-scattered part $\left(N_{\text {scat }}\right)$, which is measured separately using a zero-background holder, is then subtracted from $N_{t o t}$, as shown below:

$$
C=\left(\frac{\sum N_{\text {net }}}{\sum N_{\text {tot }}-\sum N_{\text {scat }}}\right) 100
$$

where $C$ describes the ratio between pure crystalline and amorphous phases of the sample. It gets affected by the peak position of each reflection in the mixture:

$$
N(2 \theta)=m\left[C \cdot N_{c} \cdot(2 \theta)+(1-C) \cdot I_{a} \cdot 2 \theta\right]
$$


where $N(2 \theta)$ indicates the intensity at $2 \theta$ angle, $m$ represents sample mass, while subscripts $c$ and $a$ denote pure crystalline and pure amorphous samples. $N(2 \theta)$ not only signifies intensities of the actual sample, but also pure crystalline and pure amorphous samples. With the measurement of a reference sample, these three diffractograms need to be corrected for air-scattering. The formula mentioned in Equation (22) remains as reasonable for amorphous materials as it is for crystalline materials, having similar density and elemental compositions.

\section{Safety Considerations}

The use of XRD instruments is user-friendly, however, extremely hazardous implications of $X$-ray exposure needs special attention. It is, therefore, important for both occasional users and trained personnel to consider essential safety measures for avoiding any direct and secondary radiation exposure. Harmful effects of X-ray exposure are cumulative, and can result in permanent and serious injury such as burns. For making sure that radiation exposure is negligible and under safe limits, a dosimetry badge should be worn and checked by regular users [107].

\section{Future Research Directions}

XRD is a non-destructive material characterization technique generally used for quantitative and definitive mineralogical analysis. After discussing the crystalline structure, XRD working principle, and its applications in detail, it is worthy to confer future research directions in the field of XRD. For instance, the improvement in $2 \theta$ resolution is advantageous as it would aid the XRD instrument's capabilities to analyze complex mineralogical structures [108].

Indexing algorithms have rapidly grown in the past 25 years; however, for lowresolution powder patterns or monoclinic or triclinic symmetry samples, identification of the current lattice remains a challenge [109]. Indexing is still considered a bottleneck in the powder XRD process. High-quality data works quite well with powder indexing [110]. Moreover, the increasing number of different indexing programs applied on a powder sample increases the probability of successful indexing, with the knowledge and experience of crystallographers and mineralogists.

For the collection of quick and low noise data, 2D-detectors have demonstrated highquality results for single crystals. Due to their robust data gathering capability, 2D-detectors have gained considerable attention in powder diffraction as well [111]. The doors for in situ studies have opened for structural changes including reactions, phase transitions, etc., due to the fast speed of data collection. In addition to the robustness, the diffracted intensities are obtained with high accuracy and the use of 2D-detectors allows lower sensitivity to the preferred orientations [109]. Reasonably, the next challenge for developers is curved 2Ddetectors, which would allow high Bragg angles to be collected simultaneously because of the sphere around the sample. The structure solution has undergone an intensive evolution in the previous few decades.

It is not possible to prepare all crystalline substances as single crystals of high quality and sufficient size for structural determination. Therefore, it becomes necessary to determine their structure using powder crystallography. These structure solution methods can be classified into two groups based on the type of space system used, i.e., pattern modeling-based algorithms in direct space and intensity extraction-based algorithms in reciprocal space. Hybrid models can be used if needed, based on the chemical information from a particular space. Computational chemistry can help in providing relevant information about sample crystals. The use of DFT studies can further aid in building the model, structure refinement, and validation. DFT optimization of Rietveld refined structures can assist in reaching a global minimum [112].

The use of machine learning is growing these days and XRD is no exception. A recent study by Suzuki et al. [113] used an interpretable machine learning approach for the determination of crystal systems and space groups based on the information taken by XRD 
patterns. They proposed the elimination of manual tuning during the early stages of crystal structure analysis with the advent of machine learning and the results were achieved with an accuracy of more than $90 \%$. The schematic of their approach is illustrated in Figure 18. With a similar approach to artificial intelligence, other paradigms of manual efforts can be automated for efficiently analyzing complex mineralogical samples.

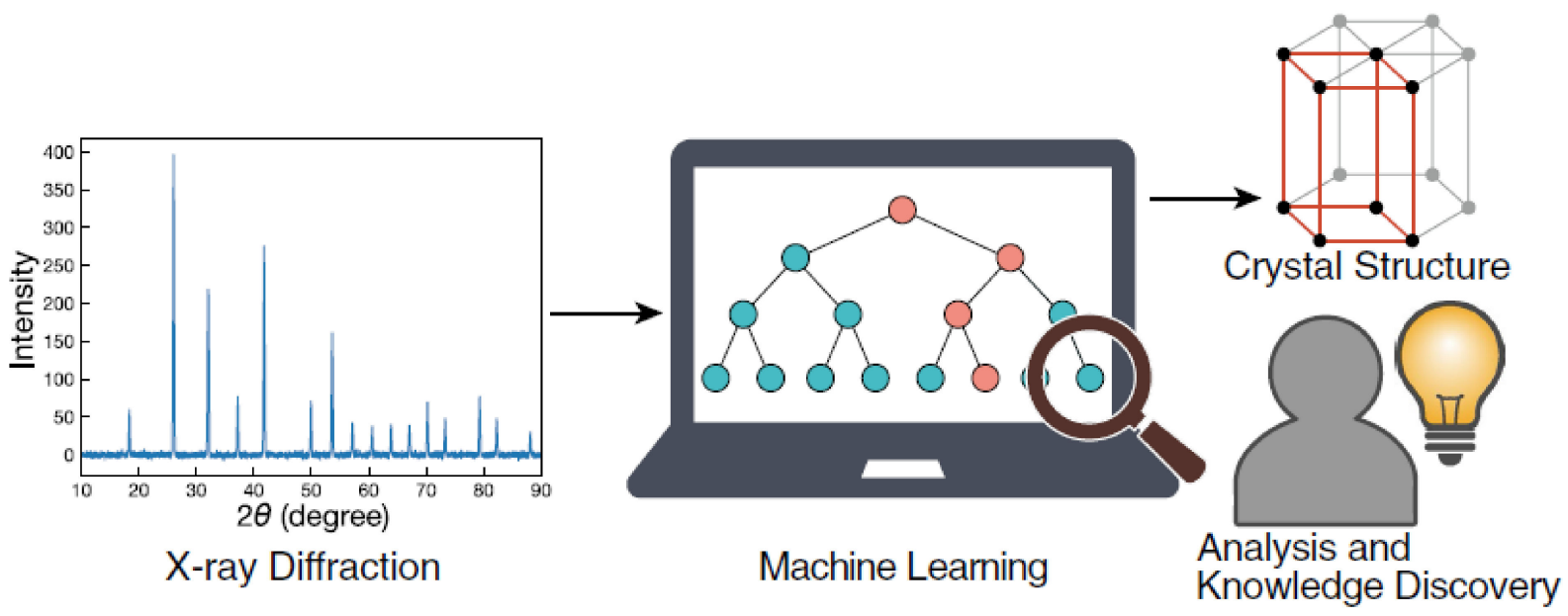

Figure 18. Schematic of the machine learning technique incorporated for identifying crystal system and space group [113]. CC-BY.

Another recent publication from Lee et al. [114] incorporated a deep learning technique for characterizing multiphase inorganic compounds providing phase identification and quantification features. They built convolutional neural network models and trained them with 1,785,405 synthetic XRD patterns, which were produced by mixing 170 inorganic compounds. These trained models accurately and promptly identified complex phases of inorganic mixtures, and the results were $100 \%$ accurate for phase identification while $86 \%$ accurate for the quantification of phase-fraction. Ziletti et al. [115] also considered a deep learning technique for the classification of crystal structures using XRD. They proposed the potential of artificial intelligence for recognizing and classifying noisy complex crystal structures.

XRD is a well-understood phenomenon, as it has been used for quite a long time for the identification and quantification of crystal structures. Several research paradigms are underway for further improving its accuracy and power to solve intricate and multiphase crystals. For example, the sample needs to be ground for XRD analysis; new investigations have been conducted for reducing this effort. Moreover, the XRD technique does not play well for mixed materials samples and its detection limit is about $2 \mathrm{wt}$ \% of the sample. Machine learning and other artificial intelligence tools are being used for improving the XRD capabilities for proper detection and quantification of involved phases. Other problems include peak overlaying and pattern indexing of non-isometric samples, which are complicated. Studies are being conducted for improving the performance of XRD techniques in these domains as well. It creates a feeling that these further advancements in XRD characterization would make it further useful, especially for identification and quantification of minerals.

\section{Conclusions}

The present paper provided a synopsis of crystal structures, the XRD principle, and its engineering applications. It discussed the future research directions for improving the XRD analysis, particularly the use of machine learning for improving the XRD accuracy and effectiveness. Following are the summarized points of this review:

- These days, several mineral characterization operations including crystallite size measurement, residual stress and strain measurement within the crystal, determination 
of crystal structure, and others are conducted with sophisticated equipment and automated procedures.

- It was covered in the present review how Bragg's theory provides practical utilization of XRD. Mineral crystal structure characterization significantly depends upon an accurate measurement of intensities and peak position of XRD patterns.

- The simplified mathematical model of Bragg's theory made the capabilities of various XRD applications possible for measuring peak intensities and positions. In the characterization of minerals, it can be said that peak position influences unit cell parameters more as compared to peak intensity or peak width.

- XRD is still tackling the same questions since its embarkment over 100 years ago. Now we have the possibility to attach cooling and heating stages, and it is possible to make measurements with variations in temperature profiles and their effect on crystal parameters. Today, XRD equipment has become more user-friendly than ever, including portable equipment and smaller benchtop models.

- XRD possesses wide application areas, however, few complex crystal structures and diffraction patterns linked with crystal shape are still misunderstood. Hence, neither Laue's nor Bragg's theory can fully comprehend XRD patterns of complex crystal structures. More investigations are needed for a better understanding of intricate XRD patterns aimed for further improvements in mineral characterization.

- Other limitations of XRD applications include powdering of the sample as XRD works well with a powdered sample. It requires particle-size fractionation, milling, and careful sample splitting, which can be laborious. Due to the lack of contrast of peaks in the diffraction pattern and overlapping interference, XRD use is complicated as well. Moreover, sample preparation, K-value calculation, and drawing calibration curves are also intricate processes limiting the value of the XRD technique. Further research is needed for improving the overall XRD testing and analyses processes, especially for complex mineralogical structures.

- It was discussed how the use of deep and machine learning tools can aid the XRD technique to improve its accuracy and effectiveness. Furthermore, with the advent of these artificial intelligence techniques, it was also discussed how XRD technique can be pushed beyond its research frontiers, especially in the area of mineral characterization.

Author Contributions: Conceptualization, Y.W.C. and R.M.S.; writing-original draft preparation, A.A.; writing-review and editing, A.A. and R.M.S.; supervision, Y.W.C. and R.M.S.; project administration, R.M.S.; funding acquisition, R.M.S. All authors have read and agreed to the published version of the manuscript.

Funding: This research was funded by Scialog ${ }^{\circledR}$, Research Corporation for Science Advancement (RCSA), and the Thistledown Foundation: 2768

Data Availability Statement: Not Applicable.

Conflicts of Interest: The authors declare no conflict of interest.

\section{Nomenclature}

$a, b, c \quad$ length of unit cell dimensions in $x, y, z$ directions, respectively

$h, k, l \quad$ Miller indices of crystallographic structure

$\alpha, \beta, \gamma \quad$ respective angles between unit cell dimensions in $x, y, z$ directions

$\alpha_{0}, \alpha_{n} \quad$ angles of incident and diffracted beams, respectively in $x$ direction

$\beta_{0}, \beta_{n} \quad$ angles of incident and diffracted beams, respectively in $y$ direction

$\gamma_{0}, \gamma_{n} \quad$ angles of incident and diffracted beams, respectively in $z$ direction

$\lambda \quad \mathrm{X}$-ray wavelength

$s_{O}, s \quad$ unit vectors along the incident and diffracted beam directions, respectively

$k_{0}, k$ unit vectors along the incident and diffracted beam directions, respectively, in the reciprocal lattice 


$\begin{array}{ll}B & \text { full width at half maximum } \\ B_{o} & \text { instrument broadening } \\ B_{L} & \text { size broadening } \\ B_{e} & \text { strain broadening } \\ B_{T} & \text { total broadening } \\ u, v, w & \text { crystallographic directions } \\ r & \text { crystallographic direction vector } \\ L & \text { atomic distance between two adjacent atoms in space } \\ n_{1}, n_{2}, n_{3} & \text { correspondence of wavelengths with integer numbers } \\ \delta & \text { dislocation density } \\ \delta_{i j} & \text { lattice tensor } \\ K & \text { Scherrer constant } \\ \varepsilon & \text { strain } \\ d & \text { space distance } \\ d_{h k l}^{*} & \text { reciprocal space distance } \\ D & \text { particle size }\end{array}$

\section{References}

1. Gilmore, C.J.; Kaduk, J.A.; Schenk., H. International Tables for Crystallography, Volume H: Powder Diffraction; Wiley: Hoboken, NJ, USA, 2019

2. Cuéllar-Franca, R.M.; Azapagic, A. Carbon capture, storage and utilisation technologies: A critical analysis and comparison of their life cycle environmental impacts. J. $\mathrm{CO}_{2}$ Util. 2015, 9, 82-102. [CrossRef]

3. Gao, J.; Li, C.; Liu, W.; Hu, J.; Wang, L.; Liu, Q.; Liang, B.; Yue, H.; Zhang, G.; Luo, D.; et al. Process simulation and energy integration in the mineral carbonation of blast furnace slag. Chin. J. Chem. Eng. 2018, 27, 157-167. [CrossRef]

4. Razeghi, M. Crystalline Properties of Solids. In Fundamentals of Solid State Engineering; Kluwer Acad.: New York, NY, USA, 2002; pp. 1-43.

5. Shackelford, J.F. Introduction to Materials Science for Engineers, 6th ed.; Pearson: London, UK, 2005.

6. Bhadeshia, H.K.D.H. Teaching Materials. Available online: http://www.phase-trans.msm.cam.ac.uk/teaching.html (accessed on 4 October 2021).

7. Sharma, R.; Bisen, D.P.; Shukla, U.; Sharma, B.G. X-RRY diffraction: A powerful method of characterizing nanomaterials. Recent Res. Sci. Technol. 2012, 4, 77-79.

8. ICDD. PDF-4+; ICDD: Newtown Square, PA, USA, 2022.

9. Pappas, N. Calculating retained austenite in steel post magnetic processing using X-ray diffraction. B. S. Undergr. Maths Exch. 2006, 4, 8-14.

10. Guma, T.N.; Madakson, P.B.; Yawas, D.S.; Aku, S.Y. X-ray diffraction analysis of the microscopies of same corrosion protective bitumen coating. Int. J. Mod. Eng. Res. 2012, 2, 4387-4395.

11. Hull, B.; John, V.B. Non-Destructive Testing; Macmillan and Hound Mills Education Ltd.: Hampshire, UK, 1989.

12. Hart, M. Bragg angle measurement and mapping. J. Cryst. Growth 1981, 55, 409-427. [CrossRef]

13. Fewster, P.F. Absolute lattice parameter measurement. J. Mater. Sci. Mater. Electron. 1999, 10, 175-183. [CrossRef]

14. Magner, S.H.; Angelis, R.J.O.; Weins, W.N.; Makinson, J.D. A historical review of retained austenite and its measurement by X-ray diffraction. Adv. X-ray Anal. 2002, 45, 85-97.

15. Jesche, A.; Fix, M.; Kreyssig, A.; Meier, W.R.; Canfield, P.C. X-ray diffraction on large single crystals using a powder diffractometer. Philos. Mag. 2018, 96, 2115-2124. [CrossRef]

16. Matsubara, E.; Shinoda, K.; Waseda, Y. X-ray Diffraction Crystallography: Introduction, Examples and Solved Problems; Springer: Berlin/Heidelberg, Germany, 2011.

17. Putnam, C.; Hammel, M.; Hura, G.L.; Tainer, J. X-ray solution scattering (saxs) combined with crystallography and computation: Defining accurate macromolecular structures, conformations and assembling in solution. Q. Rev. Biophys. 2007, 40, 191-285. [CrossRef] [PubMed]

18. Dekker, A.J. The Crystalline State. In Solid State Physics; MacMillan Co Ltd.: New York, NY, USA, 1952; pp. 1-31.

19. Aroyo, M.I. International Tables for Crystallography Volume A: Space-Group Symmetry; Wiley: Hoboken, NJ, USA, 2016.

20. Wang, L.; Essin, A.; Hermele, M.; Motrunich, O. Numerical detection of symmetry-enriched topological phases with space-group symmetry. Phys. Rev. B 2015, 91, 121103. [CrossRef]

21. Hu, S.Z.; Ng, S.W. Revisions of P-1 Space Groups to Higher Symmetry Space Groups. Chin. J. Struct. Chem. 2014, 33, 148-164.

22. Palistrant, A.F. Using the P-symmetry space groups of crystals to investigate 6D symmetry groups. Crystallogr. Rep. 2009, 54, 539-547. [CrossRef]

23. Hahn, T. Status of Volume A: Space-group Symmetry. ACTA Crystallogr. A-Found. Adv. 2005, 61, C132. [CrossRef]

24. Mizutani, U.; Sato, H. The Physics of the Hume-Rothery Electron Concentration Rule. Crystals 2017, 7, 9. [CrossRef]

25. Fultz, B.; Howe, J. Transmission Electron Microscopy and Diffractometry of Materials; Springer: Berlin/Heidelberg, Germany, 2013. 
26. Lamas, D.G.; Neto, M.D.O.; Kellermann, G.; Craievich, A.F. X-ray Diffraction and Scattering by Nanomaterials. In Nanocharacterization Techniques; William Andrew Publishing: Oxford, UK, 2017; Chapter 5; pp. 111-182.

27. Sjöström, J.K.; Bindler, R.; Granberg, T.; Kylander, M.E. Procedure for Organic Matter Removal from Peat Samples for XRD Mineral Analysis. Wetlands 2019, 39, 473-481. [CrossRef]

28. Lee, M. X-ray Diffraction for Materials Research from Fundamentals to Applications; CRC Press: Boca Raton, FL, USA, 2021.

29. Macías-Quiroga, I.F.; Giraldo-Gómez, G.I.; Sanabria-González, N.R. Characterization of Colombian Clay and Its Potential Use as Adsorbent. Sci. World J. 2018, 2018, 5969178. [CrossRef]

30. Authier, A. Dynamical Theory of X-ray Diffraction; Oxford University Press: Oxford, UK, 2001.

31. Sivia, D.S. Elementary Scattering Theory for X-ray and Neutron Users; Oxford University Press: New York, NY, USA, 2011.

32. Ameh, E.S. A review of basic crystallography and X-ray diffraction applications. Int. J. Adv. Manuf. Technol. 2019, 105, 3289-3302. [CrossRef]

33. Hammond, C. The Basics of Crystallography and Diffraction, 3rd ed.; Oxford University Press: Oxford, UK, 2009.

34. Ashcroft, N.W.; Mernin, N.D. Solid State Physics; Harcourt College Publishers: Fort Worth, TX, USA, 1976.

35. Helliwell, J.R.; Blake, A.J.; Blunden-Ellis, J.; Moore, M.; Schwalbe, C.H. Some historical extracts relevant to the discovery and application of the diffraction of X-rays by crystals to contribute to the Centennial celebration and the International Year of Crystallography. Crystallogr. Rev. 2011, 18, 3-19. [CrossRef]

36. Wood, E.A. Vocabulary of surface crystallography. J. Appl. Physiol. 1964, 35, 1306-1312. [CrossRef]

37. Fewster, P.F. Response to Fraser \& Wark's comments on a new theory for X-ray diffraction. Acta Crystallogr. Sect. A 2018, $74,457-465$.

38. Gilmore, C.J.; Barr, G.; Paisley, J. High throughput powder diffraction. A new approach to qualitative and quantitative powder diffraction pattern analysis using full pattern profile. J. Appl. Crystallogr. 2004, 37, 231-242. [CrossRef]

39. Lou, W.; Zhang, D.; Bayless, R.C. Review of mineral recognition and its future. Appl. Geochem. 2020, 122, 104727. [CrossRef]

40. Bish, D.L.; Plötze, M. X-ray Powder Diffraction with Emphasis on Qualitative and Quantitative Analysis in Industrial Min-eralogy. In Advances in the Characterization of Industrial Minerals; European Mineralogical Union: London, UK, 2010.

41. Ran, J.; Du, G.; Wang, F.Y. Rapid analysis of feldspar by X-ray diffractometry rietveld refinement method. Rock Miner. Anal. 2017, $36,489-494$.

42. Wang, C.; Yang, R.; Wang, H. Synthesis of ZIF-8/Fly Ash Composite for Adsorption of $\mathrm{Cu}^{2+}, \mathrm{Zn}^{2+}$ and $\mathrm{Ni}^{2+}$ from Aqueous Solutions. Materials 2020, 13, 214. [CrossRef]

43. Hamilton, J.; Wilson, S.; Turvey, C.; Morgan, B.; Tait, A.; McCutcheon, J.; Fallon, S.; Southam, G. Carbon accounting of mined landscapes, and deployment of a geochemical treatment system for enhanced weathering at Woodsreef Chrysotile Mine, NSW, Australia. J. Geochem. Explor. 2021, 220, 106655. [CrossRef]

44. Rodríguez, I.; Gautam, R.; Tinoco, A. Using X-ray Diffraction Techniques for Biomimetic Drug Development, Formulation, and Polymorphic Characterization. Biomimetics 2021, 6, 1. [CrossRef]

45. Haque, F.; Santos, R.M.; Chiang, Y.W. Optimizing Inorganic Carbon Sequestration and Crop Yield With Wollastonite Soil Amendment in a Microplot Study. Front. Plant Sci. 2020, 11, 1012. [CrossRef]

46. Taylor, J.; Clapp, R. New Features and Advanced Applications of Siroquant: A Personal Computer XRD Full Profile Quantitative Analysis Software Package. Adv. X-ray Anal. 1991, 35, 49-55. [CrossRef]

47. Walenta, C.; Fullmann, T. Advances in quantitative XRD analysis for clinker, cements, and cementitious additions. Int. Cent. Diffr. Data 2004, 19, 40-44. [CrossRef]

48. Henry, N.F.M.; Lipson, H.; Wooster, W.A.; Cullity, B.D. The Interpretation of X-ray Diffraction Photographs; Macmillian Ltd.: London, UK, 1961.

49. Tilley, R. Understanding Solids: The Science of Materials; John Wiley \& Sons Ltd.: West Sussex, UK, 2004.

50. Rietveld, H.M. The Rietveld method. Phys. Scr. 2014, 89, 098002. [CrossRef]

51. Rojas-Mantilla, H.D.; Ayala-Duran, S.C.; Nogueira, R.F.P. Nontronite mineral clay NAu-2 as support for hematite applied as catalyst for heterogeneous photo-Fenton processes. Chemosphere 2021, 277, 130258. [CrossRef]

52. Harris, W.; White, N. X-ray Chapter 4-Diffraction Techniques for Soil Mineral Identification. Methods Soil Anal. Part Mineral. Methods 2008, 5, 81-115.

53. Jacob, R.; Nair, H.G.; Isac, J. Structural and morphological studies of nano-crystalline ceramic $\mathrm{BaSr}_{0.9} \mathrm{Fe}_{0.1} \mathrm{TiO}_{4}$. Int. Lett. Chem. Phys. Astron. 2015, 41, 100-117. [CrossRef]

54. Barman, B.; Sarma, K.C. Structural characterization of PVA capped ZnS nano structured thin film. Indian J. Phys. 2010, 86, 703-707. [CrossRef]

55. West, A.R. Solid State Chemistry and Its Application; Wiley \& Sons: New York, NY, USA, 1974.

56. Artioli, G. Science for the cultural heritage: The contribution of X-ray diffraction. X-ray Diffr. 2013, 24, 55-62. [CrossRef]

57. Cléton, F.; Jouneau, P.H.; Henry, S.; Gäumann, M.; Buffat, P.A. Crystallographic orientation assessment by electron backscattered diffraction. Scanning 1999, 21, 232-237. [CrossRef]

58. Gräfe, M.; Klauber, C.; Gan, B.; Tappero, R.V. Synchrotron X-ray microdiffraction ( $\mu$ XRD) in minerals and environmental research. Powder Diffr. 2014, 29, 64-72. [CrossRef]

59. Lekston, Z.; Zubko, M. X-ray diffraction studies of the reversible phase transformation in niti shape memory alloy. Acta Phys. Pol. A 2016, 130, 1059-1062. [CrossRef] 
60. Lamiri, I.; Martinez-Blanco, D.; Abdelbaky, M.S.; Mari, D.; Hamana, D.; Garcia-Granda, S. Investigation of the order -disorder phase transition series in AuCu by in-situ temperature XRD and mechanical spectroscopy. J. Alloys Compd. 2019, 770, 748-754. [CrossRef]

61. McCormack, S.J.; Tseng, K.P.; Weber, R.J.; Kapush, D.; Ushakov, S.V.; Navrotsky, A.; Kriven, W.M. In Situ Determination of the $\mathrm{HfO}_{2}-\mathrm{Ta}_{2} \mathrm{O}_{5}-\mathrm{Temperature}$ Phase Diagram up to $3000{ }^{\circ} \mathrm{C}$. J. Am. Ceram. Soc. 2018, 102, 4848-4861. [CrossRef]

62. Malinov, S.; Sha, W.; Guo, Z.; Tang, C.; Long, A. Synchrotron X-ray diffraction study of the phase transformation in titanium alloys. Mater. Charact. 2002, 48, 279-295. [CrossRef]

63. Ashiri, R.; Nemati, A.; Ghamsari, M.S.; Sanjabi, S.; Aalipour, M. A modified method for barium titanate nanoparticles synthesis. Mater. Res. Bull. 2011, 46, 2291-2295. [CrossRef]

64. Bemporad, E.; Brisotto, M.; Depero, L.; Gelfi, M.; Korsunsky, A.; Lunt, A.; Sebastiani, M. A critical comparison between XRD and FIB residual stress measurement techniques in thin films. Thin Solid Films 2014, 572, 224-231. [CrossRef]

65. Singh, J.; Ranwa, S.; Akhtar, J.; Kumar, M. Growth of residual stress-free $\mathrm{ZnO}$ films on $\mathrm{SiO}_{2} / \mathrm{Si}$ substrate at room temperature for MEMS devices. AIP Adv. 2015, 5, 067140. [CrossRef]

66. Ungar, T. Strain broadening caused by dislocation. Mater. Sci. Forum 1994, 923, 166-169. [CrossRef]

67. Weertman, J.R. Hall-Petch strengthening in nano crystalline metal. Mater. Sci. Eng. A 1993, 166, 161-167. [CrossRef]

68. Subbaiah, Y.V.; Prathap, P.; Reddy, K.R. Structural, electrical and optical properties of ZnS film deposited by close-spaced evaporation. Appl. Surf. Sci. 2006, 253, 2409-2415. [CrossRef]

69. Huang, C.-Y.; Hsu, Y.-C.; Chen, J.-G.; Suryanarayanan, V.; Lee, K.-M.; Ho, K.-C. The effects of hydrothermal temperature and thickness of $\mathrm{TiO}_{2}$ film on the performance of a dye-sensitized solar cell. Sol. Energy Mater. Sol. Cells 2006, 90, 2391-2397. [CrossRef]

70. Hummer, D.R.; Heaney, P.J.; Post, J.E. Thermal expansion of anatase and rutile between 300 and $575 \mathrm{~K}$ using synchrotron powder X-ray diffraction. Powder Diffr. 2007, 22, 352-356. [CrossRef]

71. Nagash, S.; Gerhards, M.T.; Tietz, F.; Guillon, O. Coefficient of thermal expansion of Al- and Y-substituted NaSICON solid solution $\mathrm{Na}_{3+2 \mathrm{x}} \mathrm{Al}_{\mathrm{x}} \mathrm{Y}_{\mathrm{x}} \mathrm{Zr}_{2-2 \mathrm{x}} \mathrm{Si}_{2} \mathrm{PO}_{12}$. Batteries 2018, 4, 33. [CrossRef]

72. Pathak, P.D.; Vasavada, N.G. Thermal expansion of $\mathrm{NaCl}, \mathrm{KCl}$ and $\mathrm{C}_{\mathrm{S}} \mathrm{Br}$ by $\mathrm{X}$-ray diffraction and the law of corresponding states. Acta Crystallogr. Sect. A 1970, 26, 655-661. [CrossRef]

73. Bouyrie, Y.; Candolfi, C.; Pailhès, S. From crystal to glass-like thermal conductivity in crystalline minerals. Phys. Chem. Chem. Phys. 2015, 17, 19751-19758. [CrossRef]

74. Heidari, Z.; Pelalak, R.; Alizadeh, R.; Oturan, N.; Shirazian, S.; Oturan, M.A. Application of Mineral Iron-Based Natural Catalysts in Electro-Fenton Process: A Comparative Study. Catalysts 2021, 11, 57. [CrossRef]

75. Bora, J.; Deka, P.; Bhuyan, P.; Sarma, K.P.; Hoque, R.R. Morphology and mineralogy of ambient particulate matter over midBrahmaputra Valley: Application of SEM-EDX, XRD, and FTIR techniques. SN Appl. Sci. 2021, 3, 137. [CrossRef]

76. Mulenshi, J.; Gilbricht, S.; Chelgani, S.C.; Rosenkranz, J. Systematic characterization of historical tailings for possible remediation and recovery of critical metals and minerals-The Yxsjöberg case. J. Geochem. Explor. 2021, 226, 106777. [CrossRef]

77. Gong, X.; Jiang, W.; Hu, S.; Yang, Z.; Liu, X.; Fan, Z. Comprehensive utilization of foundry dust: Coal powder and clay minerals separation by ultrasonic-assisted flotation. J. Hazard. Mater. 2021, 402, 124124. [CrossRef]

78. Yuan, L.; Liu, Q.; Mathews, J.P.; Zhang, H.; Wu, Y. Quantifying the Structural Transitions of Chinese Coal to Coal-Derived Natural Graphite by XRD, Raman Spectroscopy, and HRTEM Image Analyses. Energy Fuels 2021, 35, 2335-2346. [CrossRef]

79. Li, Q.; Zhang, L.; Gao, X.; Zhang, J. Effect of pulverized fuel ash, ground granulated blast-furnace slag and $\mathrm{CO}_{2} \mathrm{curing}$ on performance of magnesium oxysulfate cement. Constr. Build. Mater. 2019, 230, 116990. [CrossRef]

80. Nergis, D.D.; Abdullah, M.M.A.B.; Sandu, A.V.; Vizureanu, P. XRD and TG-DTA Study of New Alkali Activated Materials Based on Fly Ash with Sand and Glass Powder. Materials 2020, 13, 343. [CrossRef]

81. Zhang, X.; Ge, J.; Kamali, F.; Othman, F.; Wang, Y.; Le-Hussain, F. Wettability of sandstone rocks and their mineral components during $\mathrm{CO}_{2}$ injection in aquifers: Implications for fines migration. J. Nat. Gas Sci. Eng. 2019, 73, 103050. [CrossRef]

82. Song, Q.; Zhao, H.; Jia, J.; Yang, L.; Lv, W.; Gu, Q.; Shu, X. Effects of demineralization on the surface morphology, microcrystalline and thermal transformation characteristics of coal. J. Anal. Appl. Pyrolysis 2019, 145, 104716. [CrossRef]

83. Jacob, S.R.; Wellington, D.F.; Bell, J.F.; Achilles, C.; Fraeman, A.A.; Horgan, B.; Johnson, J.R.; Maurice, S.; Peters, G.H.; Rampe, E.B.; et al. Spectral, Compositional, and Physical Properties of the Upper Murray Formation and Vera Rubin Ridge, Gale Crater, Mars. J. Geophys. Res. Planets 2020, 125, e2019JE006290. [CrossRef]

84. Fang, S.; Xu, L.; Wu, H.; Xu, Y.; Wang, Z.; Shu, K.; Longhua, X. Influence of surface dissolution on sodium oleate adsorption on ilmenite and its gangue minerals by ultrasonic treatment. Appl. Surf. Sci. 2019, 500, 144038. [CrossRef]

85. Fahad, M.; Ali, S.; Iqbal, Y. Plasma diagnostics by optical emission spectroscopy on manganese ore in conjunction with XRD, XRF and SEM-EDS. Plasma Sci. Technol. 2019, 21, 085507. [CrossRef]

86. Idris, A.; El-Zahhar, A.A. Indicative properties measurements by SEM, SEM-EDX and XRD for initial homogeneity tests of new certified reference materials. Microchem. J. 2019, 146, 429-433. [CrossRef]

87. Awadh, S.M.; Yaseen, Z.M. Investigation of silica polymorphs stratified in siliceous geode using FTIR and XRD methods. Mater. Chem. Phys. 2019, 228, 45-50. [CrossRef]

88. Qin, L.; Gao, X.; Chen, T. Influence of mineral admixtures on carbonation curing of cement paste. Constr. Build. Mater. 2019, 212, 653-662. [CrossRef] 
89. Zhang, L.; Li, Y.; Guo, H.; Zhang, H.; Zhang, N.; Hayat, T.; Sun, Y. Decontamination of U(VI) on graphene oxide/ $\mathrm{Al}_{2} \mathrm{O}_{3}$ composites investigated by XRD, FT-IR and XPS techniques. Environ. Pollut. 2019, 248, 332-338. [CrossRef]

90. Joni, I.M.; Nulhakim, L.; Vanitha, M.; Panatarani, C. Characteristics of crystalline silica $\left(\mathrm{SiO}_{2}\right)$ particles prepared by simple solution method using sodium silicate $\left(\mathrm{Na}_{2} \mathrm{SiO}_{3}\right)$ precursor. J. Phys. Conf. Ser. 2018, 1080, 012006. [CrossRef]

91. Zhou, X.; Liu, D.; Bu, H.; Deng, L.; Liu, H.; Yuan, P.; Du, P.; Song, H. XRD-based quantitative analysis of clay minerals using reference intensity ratios, mineral intensity factors, Rietveld, and full pattern summation methods: A critical review. Solid Earth Sci. 2018, 3, 16-29. [CrossRef]

92. Loganathan, N.; Bowers, G.M.; Yazaydin, A.O.; Schaef, H.T.; Loring, J.S.; Kalinichev, A.G.; Kirkpatrick, R.J. Clay Swelling in Dry Supercritical Carbon Dioxide: Effects of Interlayer Cations on the Structure, Dynamics, and Energetics of $\mathrm{CO}_{2}$ Intercalation Probed by XRD, NMR, and GCMD Simulations. J. Phys. Chem. C 2018, 122, 4391-4402. [CrossRef]

93. Sun, Z.; Vollpracht, A. Isothermal calorimetry and in-situ XRD study of the $\mathrm{NaOH}$ activated fly ash, metakaolin and slag. Cem. Concr. Res. 2018, 103, 110-122. [CrossRef]

94. Hupp, B.N.; Donovan, J.J. Quantitative mineralogy for facies definition in the Marcellus Shale (Appalachian Basin, USA) using XRD-XRF integration. Sediment. Geol. 2018, 371, 16-31. [CrossRef]

95. Li, Z.; Tang, L.; Zheng, Y.; Tian, D.; Su, M.; Zhang, F.; Ma, S.; Hu, S. Characterizing the Mechanisms of Lead Immobilization via Bioapatite and Various Clay Minerals. ACS Earth Space Chem. 2017, 1, 152-157. [CrossRef]

96. Induja, I.; Sebastian, M. Microwave dielectric properties of mineral sillimanite obtained by conventional and cold sintering process. J. Eur. Ceram. Soc. 2017, 37, 2143-2147. [CrossRef]

97. Khan, H.; Yerramilli, A.S.; D'Oliveira, A.; Alford, T.L.; Boffito, D.C.; Patience, G.S. Experimental methods in chemical engineering: X-ray diffraction spectroscopy-XRD. Can. J. Chem. Eng. 2020, 98, 1255-1266. [CrossRef]

98. Awad, M.E.; López-Galindo, A.; Sánchez-Espejo, R.; Sainz-Díaz, C.I.; El-Rahmany, M.M.; Viseras, C. Crystallite size as a function of kaolinite structural order-disorder and kaolin chemical variability: Sedimentological implication. Appl. Clay Sci. 2018, 162, 261-267. [CrossRef]

99. Silva, A.L.D.; Oliveira, A.H.D.; Fernandes, M.L.S. Influence of preferred orienation of minerals in the mineralogical identification process by X-ray diffraction. In Proceedings of the INAC 2011: International Nuclear Atlantic Conference, Belo Horizonte, MG, Brazil, 24-28 October 2011.

100. Cullity, B.; Stock, S. Elements of X-ray Diffraction; Pearson Education Limited: New Delhi, India, 2014.

101. Hermann, H.; Ermrich, M. Microabsorption Correction of X-Ray Intensities Diffracted by Multiphase Powder Specimens. Powder Diffr. 1989, 4, 189-195. [CrossRef]

102. Scarlett, N.V.Y.; Madsen, I.C.; Cranswick, L.M.D.; Lwin, T.; Groleau, E.; Stephenson, G.; Aylmore, M.; Agron-Olshinaa, N. Outcomes of the International Union of Crystallography Commission on Powder Diffraction Round Robin on Quantitative Phase Analysis: Samples 2, 3, 4, synthetic bauxite, natural granodiorite and pharmaceut. J. Appl. Crystallogr. 2002, 35, 383-400. [CrossRef]

103. De Campos, M.F.; Machado, J.C.D.R.; Achete, C.A. Metrology for a Sustainable Development Brazil. In Proceedings of the XVIII IMEKO World Congress, Rio de Janeiro, Brazil, 17-22 September 2006.

104. Igwebike-Ossi, C.D. X-ray Techniques. In Failure Analysis and Prevention; IntechOpen: London, UK, 2017.

105. Bish, D.L.; Reynolds, R.C. Sample Preparation for X-ray Diffraction. Mod. Powder Diffr. 2018, $20,73-100$.

106. Rathnaweera, T.; Ranjith, P.; Gu, X.; Perera, S.; Kumari, W.; Wanniarachchi, A.; Haque, A.; Li, J. Experimental investigation of thermomechanical behaviour of clay-rich sandstone at extreme temperatures followed by cooling treatments. Int. J. Rock Mech. Min. Sci. 2018, 107, 208-223. [CrossRef]

107. Garcia-Granada, G.; Montejo-Bernardo, J. X-ray Diffraction-Powder; Reference Module in Chemistry Molecular Sciences and Chemical Engineering; Elsevier: Amsterdam, The Netherlands, 2013.

108. Sarrazin, P.C.; Blake, D.F.; Gailhanou, M.; Chen, J.; Dera, P.; Downs, R.T.; Bristow, T.F. New Developments In X-ray Diffraction For Planetary Exploration. In Proceedings of the 49th Lunar and Planetary Science Conference, The Woodlands, TX, USA, 19-30 March 2018.

109. Černý, R. Crystal Structures from Powder Diffraction: Principles, Difficulties and Progress. Crystals 2017, 7, 142. [CrossRef]

110. Bergmann, J.; Le Bail, A.; Shirley, R.; Zlokazov, V. Renewed interest in powder diffraction data indexing. Z. Krist.—Cryst. Mater. 2004, 219, 783-790. [CrossRef]

111. Fitch, A.; Curfs, C. Ultrafast Powder Diffraction. In The Power of Powder Diffraction; Erice International School of Crystallography: Erice, Italy, 2011; pp. 103-112.

112. Smrčok, L. Powder Diffraction + Computational Methods. In The Power of Powder Diffraction; Erice International School of Crystallography: Erice, Italy, 2011; pp. 231-238.

113. Suzuki, Y.; Hino, H.; Hawai, T.; Saito, K.; Kotsugi, M.; Ono, K. Symmetry prediction and knowledge discovery from X-ray diffraction patterns using an interpretable machine learning approach. Sci. Rep. 2020, 10, 21790. [CrossRef]

114. Lee, J.-W.; Park, W.B.; Singh, S.P.; Sohn, K.-S. A deep-learning technique for phase identification in multiphase inorganic compounds using synthetic XRD powder patterns. Nat. Commun. 2020, 11, 86. [CrossRef]

115. Ziletti, A.; Kumar, D.; Scheffler, M.; Ghiringhelli, L.M. Insightful classification of crystal structures using deep learning. Nat. Commun. 2018, 9, 2775. [CrossRef] 